\title{
Discussion Paper No. 14-035 \\ The Impact of a Feed-In Tariff on Wind Power Development in Germany
}

Claudia Hitaj, Michael Schymura, and Andreas Löschel

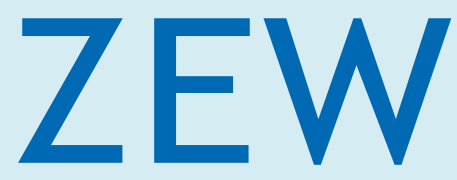

Zentrum für Europäische Wirtschaftsforschung $\mathrm{GmbH}$

Centre for European Economic Research 
Discussion Paper No. 14-035

\title{
The Impact of a Feed-In Tariff on Wind Power Development in Germany
}

\author{
Claudia Hitaj, Michael Schymura, \\ and Andreas Löschel
}

Download this ZEW Discussion Paper from our ftp server:

http://ftp.zew.de/pub/zew-docs/dp/dp14035.pdf

Die Discussion Papers dienen einer möglichst schnellen Verbreitung von neueren Forschungsarbeiten des ZEW. Die Beiträge liegen in alleiniger Verantwortung der Autoren und stellen nicht notwendigerweise die Meinung des ZEW dar.

Discussion Papers are intended to make results of ZEW research promptly available to other economists in order to encourage discussion and suggestions for revisions. The authors are solely responsible for the contents which do not necessarily represent the opinion of the ZEW. 


\title{
The Impact of a Feed-In TARIfF on Wind Power DEVELOPMENT IN GERMANY
}

\author{
Claudia Hitaj;, Michael Schymura ${ }^{\dagger}$ and Andreas Löschel \\ - May 23, $2014-$
}

\begin{abstract}
-
We estimate the impact of a feed-in tariff for renewable power on wind power investment in Germany at the county level from 1996-2010 controlling for windiness and access to the electricity transmission grid. After the Renewable Energy Law (EEG) was passed in 2000, the feed-in tariff became linked to wind power potential, such that more windy locations received a lower incentive per unit of output. We find that a $1 €$-cent $/ \mathrm{kWh}$ increase in the feed-in tariff rate would increase additions to capacity at the national level by 764 MW per year from 19962010 or 1,528 MW per year from 2005-2010. We analyze counterfactual scenarios, in which a uniform incentive is offered instead of the wind-dependent EEG incentive. Significantly more wind power plants are installed along the northern coastal counties in the uniform incentive scenario. We find that while the uniform incentive results in greater total wind power output per installed capacity, the EEG is ultimately more efficient by achieving $1 \%$ greater wind power output per euro and $3.7 \%$ greater reductions in power sector emissions per euro. In addition, we find a significant response from investors to an EEG provision that shifted the cost of transmission system upgrades from wind power developers to grid operators in 2000 . The lack of a signal on scarcity of transmission capacity has likely resulted in a distribution of wind power plants that makes suboptimal use of existing infrastructure, necessitating investment in new transmission corridors.
\end{abstract}

Keywords: Wind power, feed-in tariff, electricity transmission

JEL-Classification: Q0, Q42, Q50

The analysis and conclusions expressed here are those of the authors and may not be attributed to the Economic Research Service or the US Department of Agriculture. All remaining errors are fully attributable to the authors.

*Economic Research Service, United States Department of Agriculture, E-mail: cmhitaj@ers.usda.gov

${ }^{\dagger}$ Centre for European Economic Research (ZEW), E-mail: schymura@zew.de.

${ }^{\ddagger}$ Centre for European Economic Research (ZEW) and University of Heidelberg, E-mail: loeschel@zew.de 


\section{INTRODUCTION}

$\mathrm{R}$ ENEWABLE POWER in Germany enjoyed broad public support when a feed-in tariff for renewables was instituted in 1991. Industry response to the feed-in tariff was strong with installed wind power capacity growing nearly three-hundred-fold from $0.1 \mathrm{GW}$ in 1991 to 29.1 in 2011. Supporting renewables and promoting energy efficiency are part of a broader energy policy, the Energiewende or transformation of the energy system, which includes phasing out nuclear power by 2022 .

With the Energiewende Germany has become a global player in the green technology sector. The motivations behind the Energiewende are not only economic. According to BMU [2013] there is a popular consensus that Germany has an ethical and cultural obligation to show the world that economic competitiveness can be reconciled with sustainable development in a leading industrial nation. Despite this basic public support for the Energiewende, criticism is mounting as renewable penetration in the grid increases. Companies threaten to relocate operations outside of Germany, citing rising energy costs. Citizens complain about wind turbines and transmission lines located close to their homes. Electricity experts see an increasing risk of blackouts as investment in transmission infrastructure lags behind investment in renewable power. The European Union has investigated whether the feed-in tariffs for renewable power and industry exemptions for paying them constitute illegal subsidies. Economists and policymakers question whether the cost of supporting renewables has outpaced the benefit of reduced emissions and whether subsidizing renewable power makes sense after the inception of the European Union emissions trading scheme (ETS) in 2005.

The Energiewende had humble beginnings. Shortly after reunification of West and East Germany, the Law on Feeding Electricity into the Grid or Stromeinspeisungsgesetz (StrEG) came into effect in 1991 to promote the production of renewable power through a feed-in tariff (FIT) guaranteed over the first twenty years of the lifetime of the plant. The idea behind the law was to support renewables to reduce emissions in the power sector (1) and to prevent large electricity transmission companies from underpaying for electricity from small power producers (2) [Berchem, 2006]. The success of the StrEG took industry and government by surprise. Installed wind power capacity grew from $106 \mathrm{MW}$ in 1991 to $4435 \mathrm{MW}$ in 1999. In 2000, the German government passed the Renewable Energy Law or Erneuerbare Energien Gesetz (EEG). It maintained the structure of supporting renewables with a 20-year FIT, but clarified the allocation of interconnection costs and linked the level of the FIT to the windiness of plant locations, such that less windy locations receive a higher FIT. This location-specific FIT is an unusual component of the EEG that we investigate in our paper.

Despite continued public discussion of the Energiewende in general and renewable power in particular, basic facts about the impact of these subsidies on wind power development in Germany remain unexplored. Büsgen and Dürrschmidt [2009] review a 2007 progress report on the EEG by the Federal Ministry for the Environment, Nature Conservation and Nuclear Safety. They draw conclusions from estimates of the amount of electricity remunerated under the FIT policy and the amount of emissions reductions, but they do not estimate the additionality of the EEG - that is they assume no development of renewable power in the absence of the EEG. Frondel et al. [2010] estimate the net present cost of EEG support for renewables and provide a critique of the law, but they too do not account for additionality, nor do they allow for a location-specific FIT in the case of wind power. Diekmann et al. [2008] provide 
a comprehensive analysis and critique of the EEG, focusing on the impacts on the economy as a whole, specific industries, and the power sector. However, they too do not specifically quantify the impact of the EEG on investment in wind power.

Several studies have focused on the co-existence of the EEG and ETS, since any emission reductions achieved through the EEG in Germany would lead to a reduction in the ETS permit price and a corresponding increase in emissions. Traber and Kemfert [2009] estimate the impact of the EEG on electricity prices and emissions in the context of the ETS. They decompose the effects of the FIT into a substitution effect, triggered by the replacement of conventional by renewable sources, and a permit price effect induced via the ETS. They find that the EEG caused German consumer prices to increase by 3\%, producer prices to decrease by $8 \%$, and emissions to decrease by $11 \%$. However, European emissions are reduced only by 0.5\%, since other European countries increase emissions due to the FIT-induced drop in the permit price. Frondel et al. [2010] come to a similar conclusion. Ideally, the ETS cap would need to be adjusted according to the level of FIT support for renewables in member countries.

It has also become increasingly clear that the subsidies for renewable power have led to a much higher than expected investment in renewables with a correspondingly higher than anticipated cost. Büsgen and Dürrschmidt [2009] estimated that the cost of the EEG to the consumer would peak at $1.5 \mathrm{cent} / \mathrm{kWh}$ around 2020 , while in reality it has reached 6.24 cent/kWh in 2014.

This paper is the first study to quantify the effect of feed-in tariffs on additions to installed wind power capacity across German counties from 1995-2010, building on a similar analysis by Hitaj [2013] for the United States. The econometric analysis takes advantage of the fact the feed-in tariffs in Germany have varied both over time and across counties, allowing us to distill how great a portion of the expansion in wind power is due to the EEG as opposed to other factors. Previous studies have ignored this issue of additionality. Control variables include windiness, electricity transmission grid density, county GDP, population density, land value, voting rates for the Green Party (to capture environmental consciousness), and technological advances in wind turbines.

We find that the StrEG and EEG FIT had a significantly positive effect on wind power development. A $1 €$-cent/kWh increase in the initial FIT rate would cause capacity additions at the national level to increase by $764 \mathrm{MW}$ per year over the study period of 1996-2010 and 1,528 MW per year in 2005-2010. While the importance of the level of the FIT increased over time, the importance of ease of access to the electricity grid declined. We find that grid density has a positive effect on wind power plant installations only in 1996-1999. In 2000, the EEG shifted the burden of transmission system upgrade costs from wind power developers to grid operators, after which point grid density no longer has a significant effect on wind plant installations. We also find evidence that the regulatory change in 2004 requiring locations to meet a minimum windiness standard to remain eligible for the FIT had a significant effect, with "just" eligible locations experiencing greater wind power investment than ineligible counties.

Finally, our study allows us to further investigate a unique feature of the Renewable Energy Law. Beginning in 2000, the level of the feed-in tariff varied across locations depending on average wind speeds, such that less windy locations received higher subsidies per unit of output. The revenue a wind power plant owner receives is equal to the product of output and the FIT rate. As output increases with windiness, the FIT decreases as well by design. This 
means that revenue initially increases linearly with output and then gradually flattens out, such that locations with medium and high levels of windiness receive the same amount of revenue. This set-up induces a more uniform distribution of wind plants across the country than under a non-varying FIT.

At first glance, providing higher incentives at less windy places seems sub-optimal. The same amount of installed wind power capacity would produce a lower amount of power in the uniform case than in the clustered case. However, less money is spent on subsidizing investment in very windy areas, which might experience the same level of development with a lower incentive. Whether the overall lower cost combined with the decrease in output results in a larger or smaller output per euro is unclear a priori. In addition, power systemlevel emissions rates vary across the country, and different distributions of wind power plants result in different levels of emission reductions per euro.

Based on the estimates from the regression analysis, we analyze counter-factual scenarios, in which a uniform national incentive is offered as opposed to the EEG incentive that depends inversely on windiness. We demonstrate how the total capacity, power output, and spatial distribution of wind plants differ across these scenarios, and also estimate their costeffectiveness. We find that the EEG performs slightly better than a uniform national incentive in terms of cost-effectiveness, achieving a 1\% greater power output from wind plants per euro spent and a $3.7 \%$ greater emission reduction per euro spent than the equivalent uniform incentive. The EEG would likely perform even better if transmission congestion were taken into account, as congestion is more of an issue in areas with a high concentration of wind power plants. Thus, we find that the cost savings from linking the FIT level to windiness are substantial enough to make up for the associated reduction in output, though the overall improvement in efficiency is only minor.

\section{Bringing Wind Power ONLINe}

Despite its small land mass, Germany was the world leader in installed wind power capacity until 2007, when it was overtaken by the United States and later China. In relative terms Germany outperforms both countries, producing $7.4 \%$ of its electricity supply from wind power plants in 2012 compared with $3.4 \%$ and $2 \%$ for the United States and China, respectively [BMWi, 2013, EIA, 2013, BNEF, 2013] 1

The German government has offered generous feed-in tariffs for renewables for the past two decades, resulting in a rapid expansion of wind power in Germany and making Germany particularly suitable for a study to quantify the effects of feed-in tariffs on investment in wind power.

The profitability of a new wind plant depends on a location's wind speed profile, availability of government incentives, and access to the transmission grid. The benefit of a wind plant in terms of its contribution to abatement depends on the emissions rates of the conventional power plants its output substitutes for. This section first presents the evolution of the feed-in tariff for wind power and then provides an overview of the structure of the German

${ }^{1}$ The share of electricity generated from wind power is greater in four other countries: $30 \%$ in Denmark, $18 \%$ in Spain and Portugal, and 16\% in Ireland EIA [2013]. 
power sector, focusing on interconnection procedures for wind power plants and power sector emissions.

\subsection{Policy Incentives for Wind Power from 1991 to 2010}

The federal incentive program for wind power began in 1991 with the Stromeinspeisungsgesetz (StrEG) or Law on Feeding Electricity into the Grid. The law required utilities to purchase electricity from wind power plants at a fixed price (feed-in tariff) equal to $90 \%$ of the average retail price of electricity from two years prior and also guaranteed access to the electricity grid through interconnection. Wind power plants received the feed-in tariff (FIT) for a period of 20 years. Installed wind power capacity increased significantly from $55 \mathrm{MW}$ in 1990 to 4435 MW in 1999, supplying 1\% of electricity in 1999.

The StrEG was replaced in 2000 by the Erneuerbare Energien Gesetz (EEG) or the Renewable Energy Sources Act. Similar to the StrEG, wind power plants receive a FIT over 20 years, but the EEG stipulates a separate higher tariff for the first 5 years. The initial period with the higher tariff is extended for those wind power plants with an expected output less than $150 \%$ of reference output ${ }^{2}$ by 2 months for each $0.75 \%$ of the reference output, by which the expected output falls short of $150 \%$ of the reference output. Thus, a wind power plant with an expected output of $142.5 \%$ would receive the higher initial FIT for an additional $2 *(150-142.5) / 0.75=20$ months. This stipulation means that the EEG incentive varies across locations according to wind power potential, with less windy locations receiving more federal support per unit of output than more windy locations. Table 1 summarizes the federal incentives for wind power and installed capacity from 1991 to 2011.

The EEG revision in 2004 lowered the FIT for wind power, specified an annual FIT degression rate of $2 \%$, and excluded wind power plants with an expected output less than $60 \%$ of reference output from receiving the FIT. The latter clause ensures that wind power development does not occur in locations with very low wind resources. The 2009 revision raised FIT rates, lowered the degression rate to $1 \%$, and introduced a $0.5 €$-cent $/ \mathrm{kWh}$ system-servicesbonus during the initial period for wind power plants that fulfill certain technical requirements for grid integration of intermittent resources, such as flicker control, harmonics, and low-voltage ride through.

The costs of the FIT scheme during the first decade under the StrEG were borne by utilities, which could pass them on the customers through rate increases. Beginning with the EEG in 2000, costs were distributed directly to end-use consumers through a nationally uniform EEG surcharge on electricity bills. Energy-intensive companies facing international competition can apply to be exempted from the surcharge.

\subsection{Structure of the Electricity Sector: Deregulation and Market Power}

Deregulation of the electricity sector began in 1998 with the Energy Industry Act or Energiewirtschaftsgesetz (EnWG), which stipulated that independent power producers have open access to the transmission grid. The vertically integrated power companies controlling generation, transmission and distribution resources were required to keep separate records of these three activities. No regulatory agency was created to oversee the liberalization. Un-

${ }^{2}$ Reference output varies according to the type of turbine and is defined as the output over five years given an average wind speed of $5.5 \mathrm{~m} / \mathrm{s}$ at $30 \mathrm{~m}$ above ground. 
Table 1: Wind Power Feed-In Tariffs and Installed Capacity

\begin{tabular}{|c|c|c|c|c|}
\hline Law & Year & $\begin{array}{c}\text { Initial Incentive } \\
(€-\text { cent } / \mathrm{kWh})\end{array}$ & $\begin{array}{c}\text { Base Incentive } \\
(€-\text { cent } / \mathrm{kWh})\end{array}$ & $\begin{array}{c}\text { Installed Capacity } \\
(\mathrm{MW})\end{array}$ \\
\hline \multirow{9}{*}{ StrEG (1990) } & 1991 & \multicolumn{2}{|c|}{8.49} & 106 \\
\hline & 1992 & \multicolumn{2}{|c|}{8.45} & 174 \\
\hline & 1993 & \multicolumn{2}{|c|}{8.47} & 326 \\
\hline & 1994 & \multicolumn{2}{|c|}{8.66} & 618 \\
\hline & 1995 & \multicolumn{2}{|c|}{8.84} & 1,121 \\
\hline & 1996 & \multicolumn{2}{|c|}{8.80} & 1,549 \\
\hline & 1997 & \multicolumn{2}{|c|}{8.77} & 2,089 \\
\hline & 1998 & \multicolumn{2}{|c|}{8.58} & 2,877 \\
\hline & 1999 & \multicolumn{2}{|c|}{8.45} & 4,435 \\
\hline EEG (2000) & 2000 & 9.10 & 6.19 & 6,097 \\
\hline \multirow[t]{5}{*}{ EEG $(2004)^{a}$} & 2004 & 8.70 & 5.50 & 16,623 \\
\hline & 2005 & 8.53 & 5.39 & 18,390 \\
\hline & 2006 & 8.36 & 5.28 & 20,579 \\
\hline & 2007 & 8.19 & 5.17 & 22,194 \\
\hline & 2008 & 8.03 & 5.07 & 23,826 \\
\hline \multirow[t]{3}{*}{ EEG $(2009)^{a}$} & 2009 & $9.20^{b}$ & 5.02 & 25,703 \\
\hline & 2010 & $9.11^{b}$ & 4.97 & 27,191 \\
\hline & 2011 & $9.02^{b}$ & 4.92 & 29,071 \\
\hline
\end{tabular}

${ }^{a}$ Wind plants with an expected output less than $60 \%$ of reference output are not eligible to receive the feed-in tariffs.

${ }^{b}$ Wind plants that fulfill certain technical requirements for grid integration (flicker control, harmonics, low-voltage ride through) receive an additional $0.5 €$-cent $/ \mathrm{kWh}$ SystemServices-Bonus in the initial period.

der this setup, transparency and enforcement remained an issue, particularly since only an on-the-books separation was required. Independent power producers negotiated agreements with power companies that owned the transmission infrastructure in order to transport their electricity on the grid. However, without a regulator, large power companies could still prioritize transmission of electricity from their own generation assets over that from independent power producers.

The process of separating generation from transmission activities began in 1998 and was not completed by 2010 , the end of the study period of this paper. In 2005 , the law was changed to create a regulatory agency (Federal Network Agency or Bundesnetzagentur), and large power companies were required to separate their transmission and distribution activities from their generation activities within the company (divestment was not required). Germany's power market is very concentrated, as four power companies, RWE, EnBW, E.ON and Vattenfall, produced $82 \%$ of electricity in 2010 [EC, 2012]. Beginning only in 2010 did three of the four power companies sell or partly sell their subsidiaries controlling the transmission system 3 These large companies held market power, at least in principle, since they

${ }^{3}$ In response to inquiries from the European Commission for Competition, the four largest power companies, RWE, EnBW, E.ON and Vattenfall, moved their transmission system op- 
would have been able to favor transmitting electricity from their own generators over electricity from independent power producers. Indeed, Weigt and von Hirschhausen [2008] find realized wholesale electricity prices to be greater than competitive benchmark prices, indicating the presence of market power. Figure 7 in the Appendix depicts the control areas of the four transmission system operators.

\subsection{Interconnection and Dispatch}

The system of feed-in tariffs instituted in 1991 opened up the market to independent power producers of renewable energy, since the price of electricity was set by the government and paid for by the consumer. However, the StrEG makes no provisions for which party bears the costs of interconnection. The EEG in 2000 clarifies that renewable power plants must bear the cost of connecting to the nearest economically and technically feasible interconnection point in the grid, but the transmission operator must pay for any necessary grid upgrades to accommodate the new plant. Despite this provision, interconnection costs can be the subject of negotiation, since in some cases it is difficult to distinguish where interconnection costs end and grid upgrade costs begin [Leprich et al., 2008].

The EEG stipulates that transmission operators must give renewable power plants immediate priority for interconnection. However, the law does not elaborate on what "immediate" constitutes, nor does it provide for sanctions in the case of non-compliance [Leprich et al., 2008]. Despite the fact that the costs of the feed-in tariff can be passed on to consumers, transmission operators incur additional indirect costs, such as transactions costs and system upgrade costs (that are not directly passed on to the consumer), when renewable power plants interconnect to their grid [Leprich et al., 2008]. This can lead to tensions between TSOs and renewable power plant operators.

Ideally, a large shift in energy policy as it is codified in the EEG and envisioned in the Energiewende requires coordination between power plant developers and grid operators at the national level, so that investment in generation and transmission infrastructure can be jointly optimized. In reality, no such coordination existed until the Power Grid Expansion Act (Energieleitungsausbaugesetz) was passed in 2009 and the Network Development Plan (Netzentwicklungsplan) began in 2011.

The system of shallow interconnection fees, in which the grid operator pays for system upgrade costs, combined with priority dispatch for renewable power and a fixed feed-in tariff that does not take into account transmission constraints or system demand means that renewable power plant developers receive essentially no location signals that would allow for optimal use of the existing transmission infrastructure. Without a location signal, chances are high that renewable power plants locate in suboptimal locations, while transmission operators are required by law to provide swift interconnection and incur the cost of system upgrades. Only recently is the Federal Network Agency directly involved in coordinating transmission expansion at the national level. Joint optimization may have reduced total costs significantly - Phillips and Middleton [2012] estimates costs could have been reduced by up to $50 \%$ in Texas.

erations into newly created subsidiaries. In 2010, E.ON and Vattenfall sold their respective subsidiaries, Tennet TSO and 50Hertz Transmission, and in 2011 RWE sold a majority share in its subsidiary Amprion. TransnetBW remains a full subsidiary of EnBW. 
Expansion of the grid is necessary to transport electricity produced in the windy North to the energy intense industries and population centers located in the South and West of Germany. Building new transmission lines is a lengthy and contentious process, particularly in a country that is as densely populated as Germany. Companies in the German wind industry consider insufficient grid expansion to be the major threat to the expansion of renewable energies in Germany [Stegen and Seel, 2013].

\subsection{Intermittency and Power Sector Emissions}

Since wind power is intermittent and cannot be perfectly predicted, transmission operators must keep back-up capacity online to make up for unexpected shortfalls in output. The costs associated with this back-up capacity are generally low ${ }^{4}$ but increase with higher levels of wind power penetration. Fast-ramping natural gas plants are better suitable than slowramping coal plants for counter-balancing fluctuations in wind plant output at the sub-hourly and hourly level. If wind powe ris more likely to replace natural gas than coal, this is bad news in terms of emissions reductions, since coal plants emit roughly twice as much carbon dioxide than natural gas plants do.

Natural gas is more expensive than coal, which is another reason why wind power is more likely to substitute for power from natural gas rather than coal plants. As more renewable power plants come online, the price of electricity decreases, since plants with high marginal costs, such as natural gas, drop further down in the merit order and are dispatched less frequently:5

The expense of natural gas and its fast ramp rate mean that natural gas power plants produce less power with increased penetration of wind power in the grid. Traber and Kemfert [2011] find that at current wind power supply levels the incentives to invest in flexible natural gas power plants capable of counter-balancing the intermittent supply of wind power are insufficient. This slows down the transition to a low-carbon power sector, since the new generation of conventional plants in Germany is predominantly coal.

The benefit of renewable power plants depends heavily on location. First, some areas of the grid may experience frequent transmission constraints, in which renewable power is curtailed in favor of conventional power located closer to demand centers. Second, the abatement achieved by a renewable power plant varies across locations and depends on the configuration of the grid [Hitaj, 2014]. A subsidy for renewable power does not take this varying rate of abatement into account.

\section{DATA}

\subsection{Wind Power Installations}

This paper investigates the effect of policy incentives on wind power development in Germany from 1995 to 2010 across all 402 counties (Kreise). The dependent variable is additions

${ }^{4} 1-4 € / \mathrm{MWh}$ or $5-10 \%$ of the wholesale value of wind energy at wind energy penetrations of up to $20 \%$ of gross demand [EWEA, 2009]

${ }^{5}$ This increases the cost of the feed-in tariff program, which pays plants the difference between the electricity price and the feed-in tariff. 
to installed capacity (if any) in county $i$ in year $t$. Data on wind power installations were obtained from EEG/KWK-G][2013]. Of the 6,030 county-time observations, 2,173 or $36 \%$ had positive additions to wind power capacity. Only 19 counties $(5 \%)$ had already installed wind power plants in 1995.

Figure 1 depicts the development of installed wind power over time. There has been a steady increase in installed capacity with marked jumps after the institution of the EEG in 2000 and changes to the policy in 2004 and 2009. The slowing economy had a negative impact on investment in 2008.

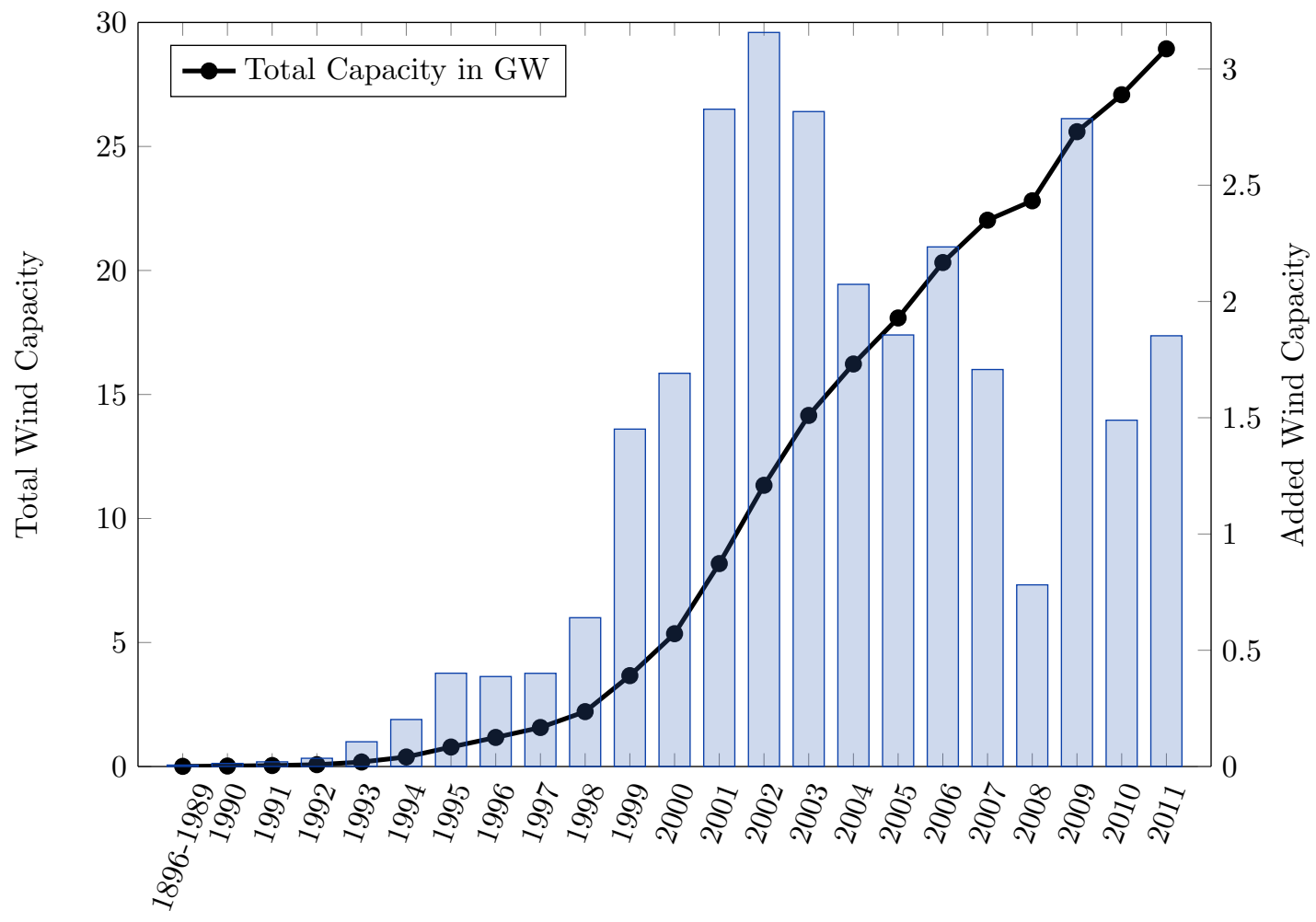

Figure 1: Total and Added Capacity

Figure 2 depicts cumulative installed windpower capacity from 1995-1999, 2000-2004, and 2005-2010 by county windpower potential. Clearly, the best (most windy) sites are developed first with investment shifting towards less-windy counties in 2000-2010, when greater incentives per unit of output were offered under the EEG than under the StrEG. 


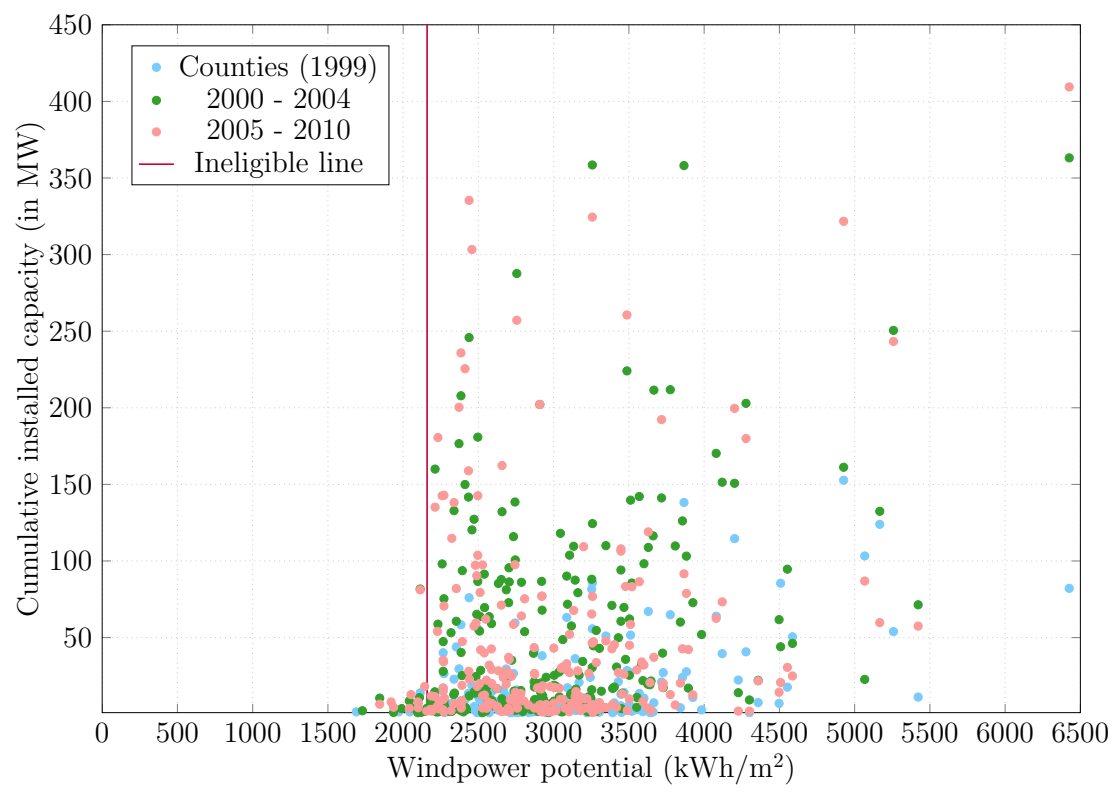

Figure 2: Cumulative additions to installed capacity by period and windpower potential

\subsection{Wind Power Potential}

Data on wind power potential at $200 \mathrm{~m}$ cell resolution were obtained from the German Weather Service [DWD, 2013]. The distribution of wind speeds at a particular location is most commonly approximated with the Weibull distribution. The DWD has calculated the Weibull parameters for each cell based on wind data collected at 218 stations from 1981 to 2000, taking into account elevation and local topography. Based on these Weibull parameters, the DWD has estimated the expected power output over five years in $\mathrm{kWh}$ per $\mathrm{m}^{2}$ of rotor swept area, assuming a hub height of $80 \mathrm{~m}$, a start speed of $3 \mathrm{~m} / \mathrm{s}$, and a stop speed of $25 \mathrm{~m} / \mathrm{s}$. The county-level spatial average of this five-year expected electricity output in $\mathrm{kWh} / \mathrm{m}^{2}$ is the measure used in this paper to account for varying wind power potential across counties. This measure offers a much finer gradation than the more commonly used wind power class or average wind speed. In addition, as the relationship between wind speed and power output is non-linear, expected wind power output can more readily be incorporated into the linear regression equation than either wind power class or average wind speed.

Figures $3 \mathrm{a}$ and $3 \mathrm{~b}$ show how wind power potential and installed capacity are concentrated in Northern Germany. However, population and economic activity are centered in the southern and western parts of Germany (Figures $3 \mathrm{c}$ and $3 \mathrm{~d}$ ). This mismatch between demand for electricity and the location of wind resources will intensify in the future, as the government is set to phase out nuclear power by 2022 , most of which is concentrated in the South $\sqrt[6]{6}$ The phaseout of nuclear power in 2022 affecting mainly the South combined with the large-scale deployment of wind power in the North presents challenges to the existing grid infrastructure.

${ }^{6}$ Nine nuclear power plants operating at full capacity $(\approx 12.7 \mathrm{GW})$ and another six nonoperating plants with a capacity of $8.4 \mathrm{GW}$ are located in the southern states of Bavaria and and Baden-Württemberg. 


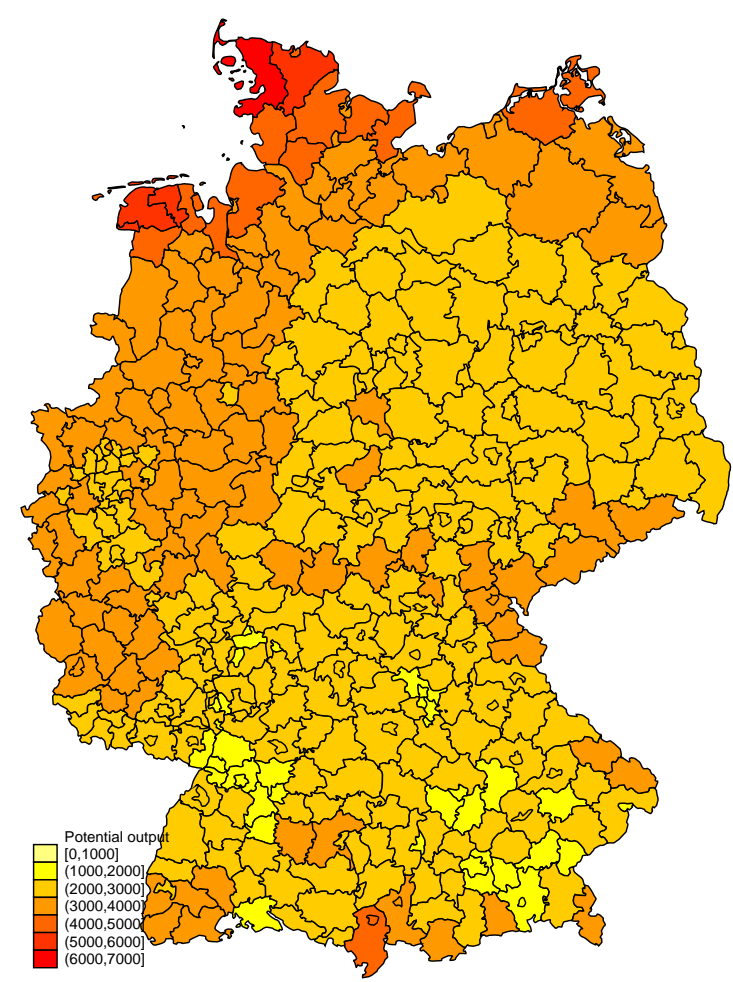

(a) Expected wind power output $\left(\mathrm{kWh} / \mathrm{m}^{2}\right)$

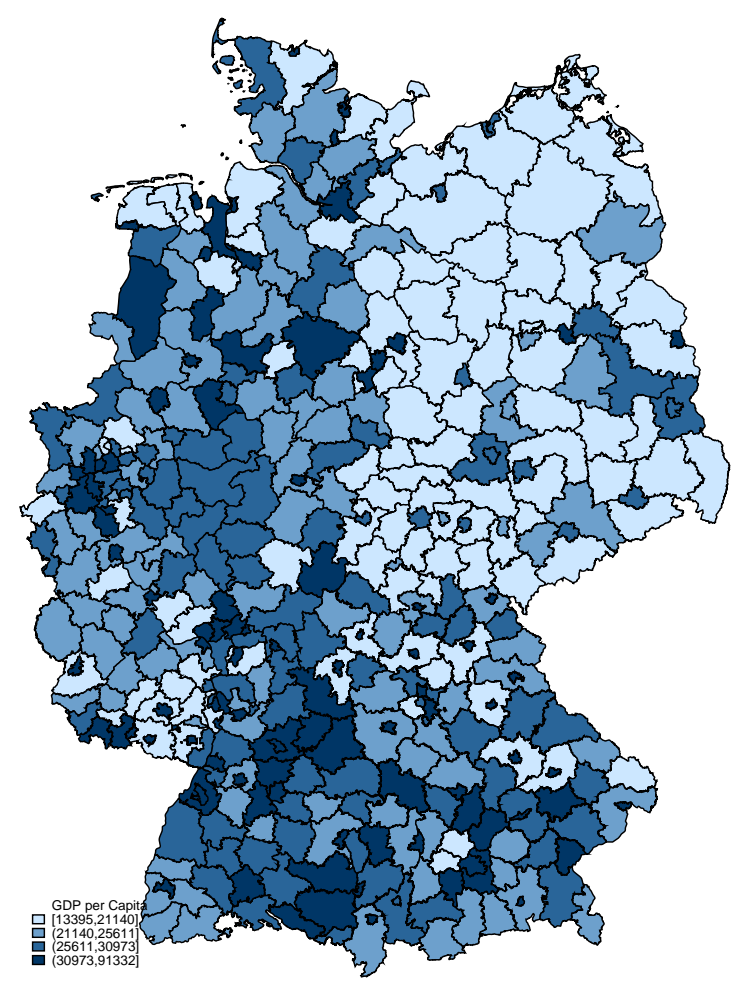

(c) GDP per capita (2010)

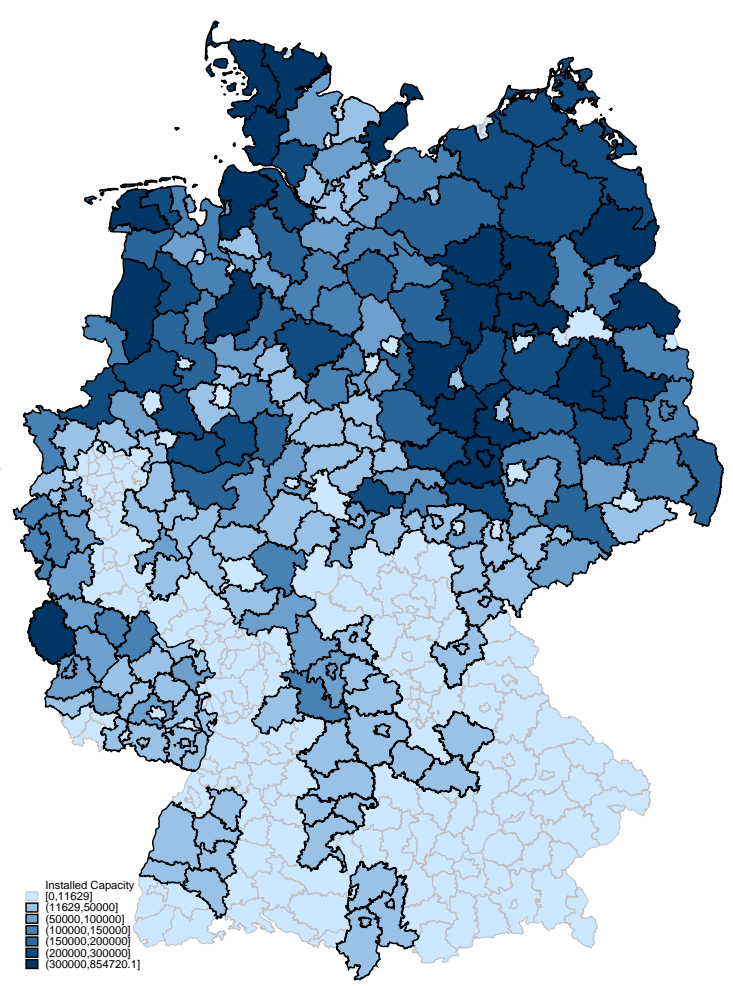

(b) Cumulative installed capacity (2010)

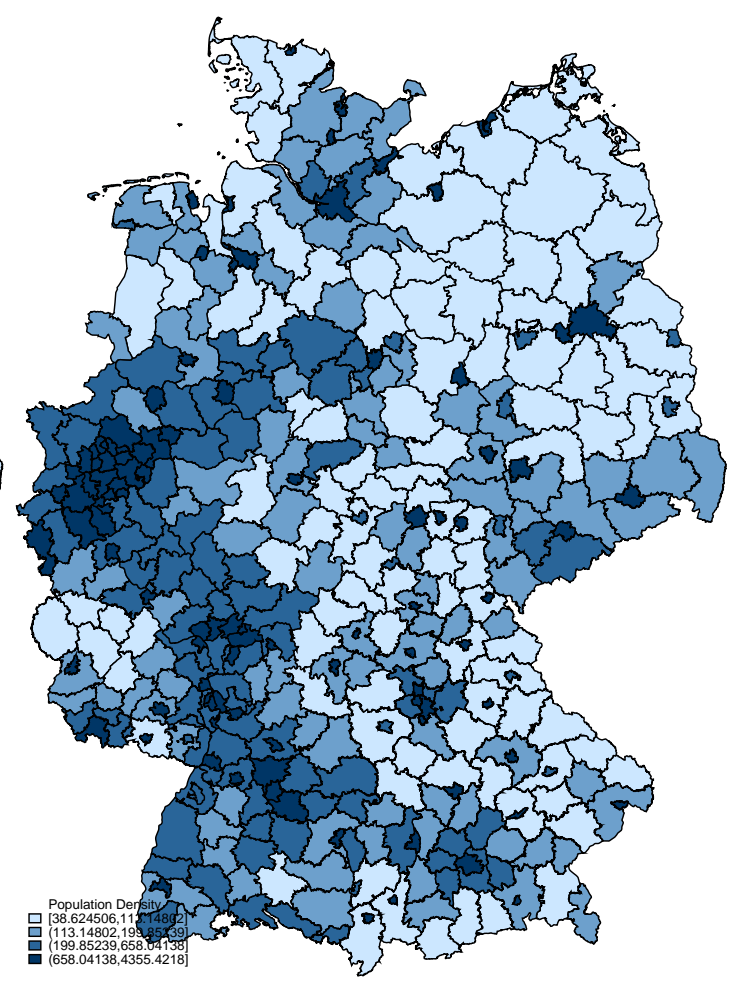

(d) Population density (2010)

Figure 3: Expected wind power output, total installed capacity, GDP per capita and population density (2010) 


\subsection{Electricity Grid}

Data on the German electricity grid were provided by the German Association of Energy and Water Industries [BDEW, 2013], ] The data contain information on transmission lines from all 934 distribution system operators. The grid density variable is calculated as the total length of transmission lines in the county divided by the county area. This variable is a measure of transmission line coverage.

\subsection{Policy Incentive Variables}

The incentive structure of the StrEG is straightforward with its standard FIT in $€$ cent/kWh available in all locations. Under the EEG however, the wind power potential of a location determines to which extent (if any) the initial five-year period with the higher tariff is expanded. Thus, the EEG incentive varies across locations according to wind power potential, and the initial and base incentives are received at different points in time during the 20 year period. Wind power potential and EEG incentive are thus linked.

A first, simple regression specification includes both the level of the initial incentive and wind power potential as regression variables. This specification does not account for the fact that the importance of the initial incentive varies across counties according to wind power potential 8 However, it is possible to track the relative importance of the incentive and wind power potential over time, which would not be possible with a single combined variable.

As a second method, this paper uses the net present value of the expected 20 year electricity output per $\mathrm{m}^{2}$ of rotor swept area of a standard wind turbine as a measure to capture the changing federal incentive over time and across counties. The DWD estimates that the reference output of the same standard wind turbine used to calculate the expected five-year electricity output in each county amounts to $4,319 \mathrm{kWh} / \mathrm{m}^{2}$. Based on this reference output, the extension of the initial period with the higher tariff can be calculated for each county. The initial period is extended for wind power plants with an expected output less than $150 \%$ of reference output by 2 months for each $0.75 \%$ of the reference output, by which the expected output falls short of $150 \%$ of the reference output. The 5 -year initial period can be extended for a maximum of 15 years, since the FIT is offered for 20 years. This means locations with an expected output less than $3,563 \mathrm{kWh} / \mathrm{m}^{2}$ receive the maximum incentive, i.e. the initial incentive for the full 20 years 9 Locations with an expected output less than $60 \%$ of reference output, which is $2,591 \mathrm{kWh} / \mathrm{m}^{2}$, are ineligible after 2004 .

The net present value of the 20 year electricity output valued at the corresponding initial and base FIT rates are calculated for each county assuming a 7\% discount rate. This incentive revenue variable in euro per $m^{2}$ rotor area captures variation in the EEG incentive across

${ }^{7}$ We thank the BDEW and Florentine Kiesel for providing the data.

${ }^{8}$ The importance varies over time as well, since the ratio of the initial to the base incentive varies: 1 from 1995-1999, 1.47 from 2000-2004, 1.58 from 2005-2008, and 1.93 from 20092010). As this is a fixed ratio over the separate time periods considered, we exclude the base incentive from the regression. Including it in the full period regression did not significantly alter the results.

${ }^{9}$ There are 90 two-month periods in 15 years. Thus, the maximum incentive is achieved at $4,319 \mathrm{kWh} / \mathrm{m}^{2} *(150 \%-(0.75 \% /$ period $* 90$ periods $))=3,563 \mathrm{kWh} / \mathrm{m}^{2}$ 
counties and over time. From 2009 onwards, it is assumed that all new wind plants meet the requirements to earn the system-services bonus of $0.5 €$-cent $/ \mathrm{kWh}$.

As a robustness check, results with non-discounted incentive revenue are presented as well. It is important to note that discounting diminishes differences in the 20-year EEG income across counties. All counties receive the initial incentive for at least 5 years. The effect of wind power potential on EEG income is felt only in later years. Non-discounted incentive revenue thus captures the heterogeneity of the EEG incentive across counties to the greatest degree.

Figure 4 shows how the EEG incentive varies according to windpower potential. The average incentive depicted in the graph is simply a weighted average of the initial and base FIT rates. For example, if a location qualifies for 7.3 years of the higher initial incentive followed by 12.7 years of the lower base incentive, the average incentive is simply $(7.3 / 20)$. initial incentive $+(12.7 / 20)$. base incentive. Locations with potential windpower output between 2,591 $\mathrm{kWh} / \mathrm{m}^{2}$ and $3,563 \mathrm{kWh} / \mathrm{m}^{2}$ receive the maximum incentive, which is the initial FIT for the entire 20 year period. The incentive decreases linearly until $6,478 \mathrm{kWh} / \mathrm{m}^{2}$, which is $150 \%$ of the reference output. Locations with greater potential output receive only the minimum incentive, which is 5 years of the initial incentive followed by 15 years of the base incentive. Correspondingly, incentive revenue increases linearly until $3,563 \mathrm{kWh} / \mathrm{m}^{2}$, after which point it gradually flattens out until reaching $6,478 \mathrm{kWh} / \mathrm{m}^{2}$, the minimum incentive level. Based on the average windpower potential in our sample of 402 counties, the initial period lasts from 5.27 to 20 years, with only 45 out of 402 counties not qualifying for an initial period extension to the full 20 years.

It is important to note that in terms of revenue, which is the FIT multiplied by power output, the EEG does not provide a greater total incentive for less windy locations. Rather, revenue flattens out, such that very windy locations receive the same revenue as somewhat less windy locations. In other words, the relationship between revenue and windpower potential never turns negative. The result of linking the FIT to windpower potential is that revenue from very windy locations is reduced to a level that is equal to (not less than) that from somewhat less windy locations.

An indicator variable, ineligible, captures the fact that locations with an expected output less than $60 \%$ of the reference output are ineligible to receive the EEG incentive beginning in August 2004 ${ }^{10}$ As the expected output variable is a spatial average of output across the county, a less strict version of the rule is applied here to better capture ineligibility. Average wind levels within a county could signal ineligibility, while parts of the county remain eligible. For this reason, the indicator variable ineligible is equal to one if the county-average expected output is less than or equal to $50 \%$ of reference output, rather than $60 \% 11$

In sum, this paper presents the results of measuring the EEG FIT through the initial incentive, as well as discounted and non-discounted incentive revenue, while controlling for eligibility with an indicator variable.

${ }^{10}$ Due to the annual nature of the data, we start the EEG 2004 reforms in 2005.

${ }^{11} \mathrm{As}$ a robustness check, we include the results using $60 \%$ as the cutoff value in Table 10 in the Appendix. 


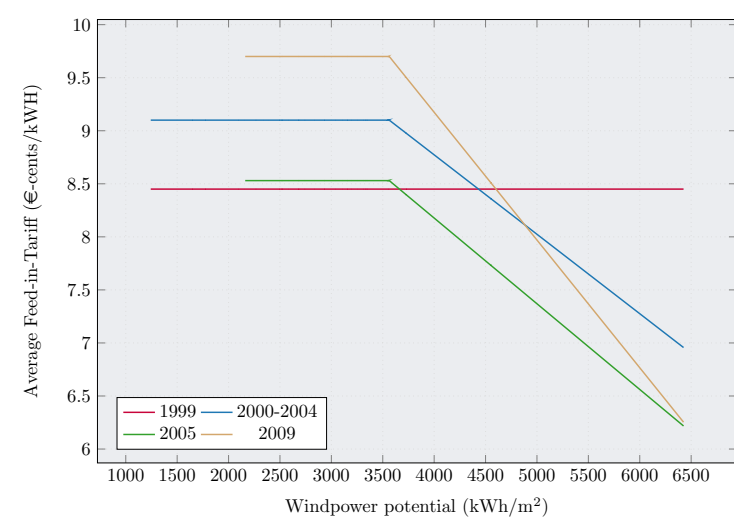

(a) Feed-In-Tariff

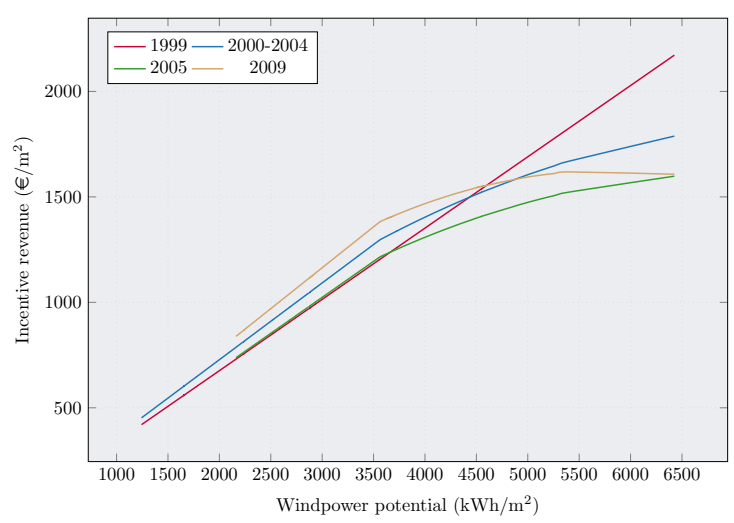

(b) Incentive Revenue

Figure 4: Feed-In-Tariff and Incentive Revenue Vary According to Windpower Potential*

* Locations with output less than $2,591 \mathrm{kWh} / \mathrm{m}^{2}$ are ineligible to receive an incentive after 2004. Locations with output between 2,591 and $3,563 \mathrm{kWh} / \mathrm{m}^{2}$ receive the minimum incentive level. The incentive increases linearly thereafter until the maximum level is reached at $6,478 \mathrm{kWh} / \mathrm{m}^{2}$.

\subsection{Socioeconomic Variables and Technological Development}

Data on county area, GDP, population density, land value, and the share of green party votes in state and federal elections were obtained from the regional database (Regionaldatenbank) of the Federal and State Statistical Offices [FSSO, 2013].

Wind power plants are less likely to be located in areas with a high population density or land value. GDP controls for county-level economic activity. As electricity demand is positively correlated with economic activity, a positive coefficient is expected. Finally, we control for technological development in wind turbine capacity and wind plant design using a flexible trinomial time trend.

\subsection{Summary Statistics}

Summary statistics are presented in Table 2. The data are divided into two groups - observations with positive additions to capacity and those with no additions to capacity. Most means and standard deviations are significantly different between the two groups. As expected, county-time observations with wind power development have on average higher wind power potential and policy incentives, as well as lower population density, land value, GDP, and grid density than those observations without wind power development. 
Table 2: Summary Statistics

\begin{tabular}{|c|c|c|c|c|c|}
\hline $\begin{array}{l}\text { Top row: no additions } \\
\text { Bottom row: positive additions }\end{array}$ & $\begin{array}{l}\text { Varies } \\
\text { Over }\end{array}$ & Mean & Std. Dev. & Min & Max \\
\hline \multirow[t]{2}{*}{ Capacity additions $(\mathrm{kW})$} & $\mathrm{CT}$ & $0 * * *$ & $0^{* * *}$ & 0 & 0 \\
\hline & & $11,627.61$ & $17,482.15$ & 0.4 & 149,614 \\
\hline \multirow[t]{2}{*}{ Lag capacity additions $(\mathrm{kW})$} & $\mathrm{CT}$ & $803.82 * * *$ & $3,405.02 * * *$ & 0 & 64,200 \\
\hline & & $10,158.78$ & $17,750.19$ & 0 & 140,879 \\
\hline \multirow[t]{2}{*}{ Lag capacity additions squared $\left(10^{3} \mathrm{~kW}^{2}\right)$} & $\mathrm{CT}$ & $12,237.32^{* * *}$ & $108,717.5^{* * *}$ & 0 & $4,121,640$ \\
\hline & & $418,125.1$ & $1,438,297$ & 0 & $1.98 \mathrm{e}+07$ \\
\hline \multirow[t]{2}{*}{ Windpower potential $\left(\mathrm{kWh} / \mathrm{m}^{2}\right)$} & $\mathrm{CT}$ & $2,583.04 * * *$ & $574.71 * * *$ & 1243 & 5422 \\
\hline & & $3,094.72$ & 750.36 & 1624 & 6426 \\
\hline \multirow[t]{2}{*}{ Incentive revenue $\left(€ / \mathrm{m}^{2}, 7 \%\right.$ discount $)$} & $\mathrm{CT}$ & $480.90 * * *$ & $106.85^{* * *}$ & 211.48 & 985.68 \\
\hline & & 575.49 & 127.84 & 302.40 & $1,203.60$ \\
\hline \multirow[t]{2}{*}{ 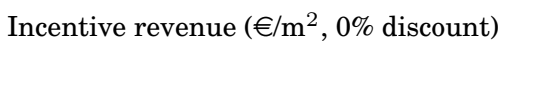 } & $\mathrm{CT}$ & $907.56^{* * *}$ & $200.66^{* * *}$ & 399.25 & $1,860.83$ \\
\hline & & $1,083.21$ & 235.05 & 570.88 & $2,272.23$ \\
\hline \multirow[t]{2}{*}{ Incentive revenue $\left(€ / \mathrm{m}^{2}, 3 \%\right.$ discount $)$} & $\mathrm{CT}$ & $674.73^{* * *}$ & $148.56^{* * *}$ & 296.99 & 1384.22 \\
\hline & & 805.21 & 174.50 & 424.66 & $1,690.26$ \\
\hline \multirow[t]{2}{*}{ Initial incentive (€-cent/kWh) } & $\mathrm{CT}$ & $8.81^{* * *}$ & $.46^{* * *}$ & 8.03 & 9.70 \\
\hline & & 8.88 & .43 & 8.03 & 9.70 \\
\hline \multirow[t]{2}{*}{ Base incentive (€-cent/kWh) } & $\mathrm{CT}$ & $6.62^{* *}$ & $1.54^{* *}$ & 4.97 & 8.84 \\
\hline & & 6.51 & 1.40 & 4.97 & 8.84 \\
\hline \multirow[t]{2}{*}{ Ineligible for incentive $(0 / 1)$} & $\mathrm{CT}$ & $.10 * * *$ & $.29 * * *$ & 0 & 1 \\
\hline & & .02 & .12 & 0 & 1 \\
\hline \multirow[t]{2}{*}{ Area $\left(\mathrm{km}^{2}\right)$} & $\mathrm{C}$ & $641.48 * * *$ & $516.14 * * *$ & 35.7 & $4,751.33$ \\
\hline & & $1,335.16$ & 818.97 & 35.7 & $5,811.52$ \\
\hline \multirow[t]{2}{*}{ Grid density $\left(\mathrm{km} / \mathrm{km}^{2}\right)$} & $\mathrm{CT}^{\dagger}$ & $27.24^{* * *}$ & $128.72 * * *$ & 0 & $1,835.23$ \\
\hline & & 6.03 & 43.99 & 0 & $1,790.16$ \\
\hline \multirow[t]{2}{*}{ GDP (billion $€$ ) } & $\mathrm{CT}$ & $5.72^{* * *}$ & $8.50 * * *$ & .74 & 98.75 \\
\hline & & 4.79 & 6.58 & .8 & 92.17 \\
\hline \multirow[t]{2}{*}{ Population per $\mathrm{km}^{2}$} & $\mathrm{CT}$ & $671.94^{* * *}$ & $756.04^{* * *}$ & 39.04 & $4,355.42$ \\
\hline & & 249.86 & 346.73 & 38.62 & $3,865.81$ \\
\hline \multirow[t]{2}{*}{ Land value $\left(€ / \mathrm{m}^{2}\right)$} & CT & $123.01^{* * *}$ & $112.59^{* * *}$ & 0 & $1,296.84$ \\
\hline & & 55.60 & 55.22 & 1.74 & 813.44 \\
\hline \multirow[t]{2}{*}{ Green Party votes ( $\%$, state) } & $\mathrm{CT} \ddagger$ & $7.28 * * *$ & $3.94 * * *$ & 0.94 & 28.27 \\
\hline & & 5.38 & 2.95 & 1.00 & 23.52 \\
\hline \multirow[t]{2}{*}{ Green Party votes ( $\%$, federal) } & $\mathrm{CT} \ddagger$ & $7.61^{* * *}$ & $3.46^{* * *}$ & 2.27 & 28.68 \\
\hline & & 7.93 & 2.64 & 2.15 & 28.68 \\
\hline
\end{tabular}

Variables vary across counties (C) and/or over time (T).

$\dagger$ The grid variables vary from 2008 onwards. The values for 1995 until 2007 are fixed. Counties with no installed transmission lines are typically densely populated and contain only lower voltage distribution lines.

$\ddagger$ Since elections take place every 4-5 years, the values between the elections are interpolated.

Differences in means and standard deviations may be significant at the $1 \%(* *), 5 \%(* *)$, or $10 \%(*)$ level. Difference in means is tested with a t-test allowing for unequal variances. Difference in standard deviation is tested with Bartlett's test.

\section{Empirical STRATEGY}

The sample includes all 402 counties from 1996 to 2010 (with lag capacity additions necessitating the exclusion of 1995) for a total of 6,030 observations. Positive additions to installed wind power capacity occurred in only $36 \%$ of county-time observations, which means the dependent variable is equal to zero for $64 \%$ of the observations. The Tobit model first developed 
by Tobin [1958] is designed to handle this type of corner solution or censoring of the dependent variable, where $y_{i t}$ is zero with positive probability and close to continuous for $y_{i t}>0$. The random-effects panel Tobit estimators are obtained by maximum likelihood.

Let latent wind power capacity additions $y_{i t}^{*}$ depend on the vector $X_{i t}$, consisting of the independent variables discussed in the data section, such that

$$
y_{i t}^{*}=X_{i t} \beta+\epsilon_{i t}
$$

and

$$
\epsilon_{i t}=\nu_{i}+\xi_{i t}
$$

for all counties $i=1, \ldots, N$ and all time periods $t=1, \ldots, T$. As corner solutions are possible, the observed variable is

$$
y_{i t}= \begin{cases}y_{i t}^{*} & \text { if } y_{i t}^{*}>0 \\ 0 & \text { if } y_{i t}^{*} \leq 0 .\end{cases}
$$

The error term $\epsilon_{i t}$ is composed of a time-invariant county-specific random effect $\nu_{i}$ and an idiosyncratic error $\xi_{i t}$ that varies over time and across counties. Assume that $\forall i \neq j, t \neq q$

$$
\begin{array}{ll}
\mathbb{E}\left[\nu_{i} \nu_{j}\right]=0, & \nu_{i} \equiv N\left(0, \sigma_{\eta}^{2}\right) \\
\mathbb{E}\left[\xi_{i t} \xi_{i q}\right]=0, & \xi_{i} \equiv N\left(0, \sigma_{\xi}^{2}\right)
\end{array}
$$

and that $\nu_{i}$ is orthogonal to $X_{i t}$. This latter assumption requires that any unobserved timeinvariant county-specific variables, that affect wind power and are thus contained in $\nu_{i}$, are uncorrelated with the independent variables. Elevation and land use or ground cover may make some counties particularly unsuitable for hosting wind turbines, but it is unlikely that these characteristics should be systematically correlated with the independent variables.

The zero covariance assumption means that errors are not correlated across counties or over time. This assumption is violated if, for example, firms with existing installed capacity prefer investing in neighboring counties or in the same county in some later period to take advantage of economies of scale to reduce costs. However, the potential cost savings are small compared to total costs, which are comprised largely of the wind turbine cost.

The regression equation is also estimated via random-effects ordinary least squares as a robustness check.

\subsection{Counterfactual Scenarios}

A unique feature of the EEG is that incentives depend on wind power potential, with less windy locations receiving a higher incentive per unit of output than more windy locations. This paper analyzes several counterfactual scenarios, in which a uniform incentive is applied to all locations to compare wind power development across the different regions. Each scenario is associated with a different geographical roll-out of wind power across the regions, and thus a different level of wind power output, total cost of the subsidy, and emissions. Based on the regression estimates for the full sample period (1996-2010), annual additions to installed capacity are predicted under the EEG as well as different levels of uniform incentives for the 2000-2010 period. 
Equation 1 gives the predicted capacity additions $\hat{y}_{i t}$ in county $i$ in year $t$, where $\hat{\beta}$ and $\hat{\sigma}_{\xi}$ are the estimated coefficients from the regression analysis and $\phi$ and $\Phi$ are the Normal probability density function and cumulative distribution function.

$$
\hat{y}_{i t}=\mathbb{E}\left[y_{i t} \mid x_{i t}, y_{i t}>0\right]=X_{i t} \hat{\beta}+\hat{\sigma}_{\xi} \frac{\phi\left(X_{i t} \hat{\beta} / \hat{\sigma}_{\xi}\right)}{\Phi\left(X_{i t} \hat{\beta} / \hat{\sigma}_{\xi}\right)}
$$

A counterfactual scenario with a uniform incentive (as opposed to a wind-dependent incentive) is analyzed by replacing the EEG incentives with the uniform incentive before predicting additions to capacity. A difficulty arises from the fact that lag capacity is one of the explanatory variables in the vector $X_{i t}$. Keeping realized capacity additions under the EEG as the lag capacity variable would bias the predictions towards maintaining the geographical distribution of wind power development under the EEG. For this reason, capacity additions in 2000 are predicted using 1999 data. In each subsequent year $t \geq 2000$, the predicted addition $\hat{y}_{i t}$ is then used as lag capacity for predicting $\hat{y}_{i, t+1}$ in the following year.

Each subsidy scenario $s$ is associated with different capacity additions $\hat{y}_{i t}$ over the $i=$ $1, \ldots, N$ counties and $t=1, \ldots, T$ years. The wind power output $O(s)$ over 20 years of all the plants installed over the $N$ counties and $T$ years is calculated as follows:

$$
O(s)=\sum_{t=1}^{T} \sum_{i=1}^{N} 20 \cdot \hat{y}_{i t}(s) \cdot k \cdot w_{i}
$$

where $k$ is the capacity factor equal to $0.3{ }^{12}$ and $w_{i}$ is the wind power potential in county $i$. The wind power potential is calculated as the one-year output in $\mathrm{kWh}$ per square meter rotor area (the wind power potential variable divided by 5 ) times the square meter per $\mathrm{kW}$ of a typical $2 \mathrm{MW}$ turbine at $80 \mathrm{~m}$ hub height $\left(5,026.5 \mathrm{~m}^{2} / 2 \mathrm{MW}=2,513.25 \mathrm{~m}^{2} / \mathrm{MW}\right)$, such that $w_{i}$ is in units of $\mathrm{kWh} / \mathrm{MW}$. Output $O$ is in $\mathrm{kWh}$ per 20 -year plant life.

The total cost $C$ is given by equation 3 , where $s_{i t}$ is the average incentive received in county $i$ in year $t$ in euros per $\mathrm{kWh}$, such that $C$ is in euros per year.

$$
C(s)=\sum_{t=1}^{T} \sum_{i=1}^{N} \hat{y}_{i t}(s) \cdot k \cdot w_{i} \cdot s_{i t}
$$

Equation 4 gives the total emission reductions $E(s)$ from wind power output replacing output from conventional power plants. The emissions rate $e_{i}$ is time-invariant and varies over states (Bundesland) and is given in $\mathrm{kg}$ of $\mathrm{CO}_{2}$-equivalent per $\mathrm{kWh}$ (Table 8). The ideal measure would be an emissions rate at the county level that also varies over time, but these data are not available. Total emission reductions $E$ are given in ton of $\mathrm{CO}_{2}$-equivalent per year.

$$
E(s)=\sum_{t=1}^{T} \sum_{i=1}^{N} \hat{y}_{i t}(s) \cdot k \cdot w_{i} \cdot e_{i}
$$

The subsidy scenarios $s$ can be ranked according to their efficiency, as measured by the $\mathrm{kWh}$ output per $€, O(s) / C(s)$, and by emission reductions in ton of $\mathrm{CO}_{2}$-equivalent per $€$, $E(s) / C(s)$.

${ }^{12} \mathrm{~A}$ wind power plant does not run at full capacity at all times. A capacity factor equal to 0.3 means that the wind plant is assumed to produce $30 \%$ of its potential output. 


\section{Results AND Discussion}

Tables 3, 4, and 5 present the regression results using different methods to capture the incentive program: initial incentive with windpower potential (Table 3) and the combined measure of discounted (Table 4) and non-discounted (Table 4) incentive revenue.

Including the level of the initial incentive and windpower potential as separate regressors does not account for the fact that the relative importance of the initial incentive changes with windpower potential (and over time). This is accomplished by computing a combined measure, incentive revenue, which is equal to the net present value of the expected electricity output over 20 years valued at the corresponding initial and base FIT rates assuming a 7\% discount rate. It is thus a non-linear function of windpower potential, our measure of windiness, which is therefore excluded from the regression. In each case, the regression results are estimated for the full 1996-2010 time period, the StrEG period of 1996-1999, the EEG period from 2000-2010, as well as a breakdown of 2000-2004 and 2005-2010 to account for the 2004 change to the EEG when some areas became ineligible for the incentive.

The regression results are robust across specifications. StrEG and EEG incentives, windpower potential, lag capacity additions, county area, and GDP have a significantly positive effect on wind power development, while squared lag capacity additions, population density, and land value have a negative effect. A $1 €$-cent/kWh increase in the FIT would lead to an increase in capacity additions of around 1.9 MW per county per year over the entire 1996-2010 period. The effect would be even greater in 2005-2010 with capacity additions increasing by 3.8 MW per county in the 2005-2010 period. At the national level, this amounts to $764 \mathrm{MW}$ per year for 1996-2010 and 1,528 MW per year for 2005-2010, calculated by multiplying with regression estimates by the 402 counties.

In all three Tables, access to the grid as measured by grid density emerges as an important determinant of wind power investment only during the StrEG from 1996-1999. The lack of significance in later years reflects the fact that new renewable power plants were guaranteed access to the grid with grid operators paying for any necessary upgrade costs. The allocation of interconnection costs between plant developers and grid operators changed in 2000 with the EEG. While the StrEG did not specify how costs are allocated, the EEG shifted the majority of the costs (system upgrade costs) to grid operators. As expected, beginning in 2000 grid interconnection costs no longer figure into wind power developer's location decisions. This system of shallow interconnection fees with essentially no location signal to developers has likely led to a distribution of wind power plants across Germany that makes suboptimal use of the existing grid infrastructure, requiring more grid upgrades than otherwise necessary. In the United States, renewable power plants are for the most part responsible for system upgrade costs, which acts as a location signal to developers. A similar study of wind power development in the United States finds that transmission line coverage has a significant positive effect on additions to wind power capacity [Hitaj, 2013].

Table 3 shows how the relative importance of windpower potential, the incentive level, and grid density changes over time. Grid density becomes less important beginning in 2000 while windpower potential and the level of the initial FIT become more important. This indicates that in later years, the EEG incentive becomes the main driver of wind power development. Table 4 confirms this result. The coefficient on discounted incentive revenue on capacity additions increases from 3.36 in 1996-1999 to 16.11 in 2000-2010, while the effect 
of other variables, such as grid density or lag capacity additions declines. This result is expected, since the "best" wind power locations are developed first. As time goes on, the remaining sites become less and less desirable, such that the relative importance of any incentive increases. However, this result also reflects the changing nature of the FIT in Germany from the uniform incentive during the StrEG to the wind-dependent design during the EEG. Under the EEG, wind power development is supported more heavily in less suitable (less windy) locations, such that the incentive gains, by design, greater relative importance during the EEG as compared with the StrEG.

As a robustness check, Table 5 shows the regression results using non-discounted incentive revenue to capture the EEG. Again, the coefficient on non-discounted incentive revenue on capacity additions increases from 1.78 in 1996-1999 to 8.57 in 2000-2010. The model is also estimated using ordinary least squares (Table 9 in the Appendix), yielding similar results.

It is difficult to measure the effect of ineligibility on wind capacity additions, since data are at the county level. Average wind levels within a county could signal ineligibility, while parts of the county remain eligible. The indicator variable, ineligible, measured with a less stringent $50 \%$ reference output cutoff, is not significant. However, the change in regulations in 2004 making less windy sites ineligible is not meaningless; ineligibility measured at $60 \%$ of reference output appears to capture "just" eligible counties, which has a significant positive effect on capacity additions (Table 10 . Ineligibility measured at $50 \%$ is conversely not significantly negative, since these counties may be undesirable in any case 13

Thus, the regulatory change that took place in 2004 marking less windy sites as ineligible for the incentive had a significant effect on capacity additions with wind power developers taking advantage of available incentives up until the ineligibility cutoff. While such a measure is likely to reduce investment in windpower in locations with suboptimally low windpower potential, the design as a sharp cut-off point is not efficient as the net benefits of windpower plants do not drop from a large positive value to zero at some particular level of windpower potential. The decline is likely to be smooth, which an efficient incentive design would reflect.

From 1996-1999, the county-level share of Green Party votes in the state election has a positive impact on wind power development, suggesting that wind developers take local attitudes into account when siting turbines. Conversely, support for the Green party at the federal level has a negative effect, probably because many non-environmentalists voted Green as a rejection of the ruling conservative party. This relationship flipped by 2005-2010. At this later stage, the EEG formed an important part of the national debate, and citizens recognized that subsidies were set by the federal government. Support for the Green party at the federal level thus has a positive effect on wind power development. The negative effect of the share of Green Party votes in state elections indicates that citizens may support wind power in general but resist development in their immediate surroundings (NIMBYism). As Green Party voters, these citizens presumably place a high premium on their local environment and may oppose the visual and auditory impacts of wind turbines on the local community.

${ }^{13}$ Of the 72 ineligible counties measured at a $50 \%$ cut-off, 30 counties experienced windpower development by 2004 . However, cumulative capacity in those counties in 2004 reached $162 \mathrm{MW}$, which is only $0.6 \%$ of the total installed capacity of 26,600 MW. 


\section{Table 3: Wind Power Capacity Tobit Marginal Effects - Initial Incentive}

\begin{tabular}{|c|c|c|c|c|c|}
\hline Dependent Variable & Full & StrEG & EEG I & EEG II & EEG \\
\hline Capacity additions (kW) & $1996-2010$ & 1996-1999 & $2000-2004$ & $2005-2010$ & $2000-2010$ \\
\hline \multirow[t]{2}{*}{ Lag capacity additions (kW) } & $0.109 * * *$ & $0.191^{* * *}$ & $0.215^{* * *}$ & $0.0569 * *$ & $0.103^{* * *}$ \\
\hline & $(0.01)$ & $(0.03)$ & $(0.03)$ & $(0.02)$ & $(0.02)$ \\
\hline \multirow{2}{*}{$\begin{array}{l}\text { Lag capacity additions squared } \\
\qquad\left(10^{3} \mathrm{~kW}^{2}\right)\end{array}$} & $-0.000556^{* * *}$ & $-0.00246^{* * *}$ & $-0.00147 * * *$ & -0.000234 & $-0.000584^{* *}$ \\
\hline & $(0.00)$ & $(0.00)$ & $(0.00)$ & $(0.00)$ & $(0.00)$ \\
\hline \multirow[t]{2}{*}{ Windpower potential $\left(\mathrm{kWh} / \mathrm{m}^{2}\right)$} & $1.933 * * *$ & $0.624^{* * *}$ & $2.516^{* * *}$ & $1.563 * * *$ & $2.347 * * *$ \\
\hline & $(0.24)$ & $(0.12)$ & $(0.35)$ & $(0.34)$ & $(0.32)$ \\
\hline \multirow[t]{2}{*}{ Initial incentive (€-cent/kWh) } & $1902.1^{* * *}$ & 1111.9 & & $3785.1^{* * *}$ & $2623.5^{* * *}$ \\
\hline & $(209.86)$ & $(2344.17)$ & & $(415.82)$ & $(353.48)$ \\
\hline \multirow[t]{2}{*}{ Ineligible for incentive $(0 / 1)$} & 361.5 & & & -1087.1 & 699.8 \\
\hline & $(535.86)$ & & & $(622.67)$ & $(705.98)$ \\
\hline \multirow[t]{2}{*}{ Area $\left(\mathrm{km}^{2}\right)$} & $2.393 * * *$ & $0.690 * * *$ & $2.962^{* * *}$ & $2.585 * * *$ & $2.984 * * *$ \\
\hline & $(0.28)$ & $(0.13)$ & $(0.43)$ & $(0.39)$ & $(0.38)$ \\
\hline \multirow[t]{2}{*}{ Grid density $\left(\mathrm{km} / \mathrm{km}^{2}\right)$} & 1.413 & $1.591^{*}$ & -5.137 & 1.296 & -0.682 \\
\hline & $(1.61)$ & $(0.68)$ & $(5.81)$ & $(2.86)$ & $(3.16)$ \\
\hline \multirow[t]{2}{*}{ GDP (billion $€$ ) } & $103.5^{* * *}$ & $85.78^{* * *}$ & $156.0^{* * *}$ & $85.50^{*}$ & $111.8^{* *}$ \\
\hline & $(27.53)$ & $(14.36)$ & $(44.58)$ & $(35.63)$ & $(35.91)$ \\
\hline \multirow[t]{2}{*}{ Population per $\mathrm{km}^{2}$} & $-1.421 * * *$ & $-0.714^{* *}$ & $-2.041^{* *}$ & -1.165 & $-1.642^{* *}$ \\
\hline & $(0.42)$ & $(0.23)$ & $(0.69)$ & $(0.60)$ & $(0.57)$ \\
\hline \multirow[t]{2}{*}{ Land value $\left(€ / \mathrm{m}^{2}\right)$} & $-9.030 * * *$ & $-5.817 * * *$ & $-18.62^{* * *}$ & -6.972 & $-11.83^{* * *}$ \\
\hline & $(2.25)$ & $(1.49)$ & $(4.21)$ & $(3.68)$ & $(3.08)$ \\
\hline \multirow[t]{2}{*}{ Green Party votes (\%, state) } & -12.34 & $130.1^{* *}$ & 207.8 & -121.5 & -30.91 \\
\hline & $(46.17)$ & $(47.77)$ & $(123.80)$ & $(78.41)$ & $(67.15)$ \\
\hline \multirow[t]{2}{*}{ Green Party votes (\%, federal) } & -56.59 & $-324.5^{* * *}$ & -192.3 & -35.60 & -31.78 \\
\hline & $(66.82)$ & $(82.03)$ & (140.29) & (109.06) & (89.59) \\
\hline \multirow[t]{2}{*}{ Time index } & $973.6^{* * *}$ & -640.6 & 24104.1 & $83322.5^{* * *}$ & -1415.2 \\
\hline & $(294.42)$ & $(424.40)$ & $(16544.01)$ & $(20519.90)$ & (1802.28) \\
\hline \multirow[t]{2}{*}{ Time index squared } & -47.80 & 154.8 & -2487.3 & $-5941.9 * * *$ & 203.4 \\
\hline & $(36.72)$ & (81.10) & $(2104.35)$ & $(1517.31)$ & (179.49) \\
\hline \multirow[t]{2}{*}{ Time index cubed } & -0.296 & & 79.56 & $137.9 * * *$ & -8.640 \\
\hline & $(1.36)$ & & $(87.82)$ & $(37.04)$ & $(5.67)$ \\
\hline Counties & 402 & 402 & 402 & 402 & 402 \\
\hline Uncensored observations & 2,173 & 501 & 884 & 788 & 1,672 \\
\hline Observations & 6,030 & 1,608 & 2,010 & 2,412 & 4,422 \\
\hline
\end{tabular}

${ }^{*} \mathrm{p}<0.10,{ }^{* *} \mathrm{p}<0.05,{ }^{* * *} \mathrm{p}<0.01$, standard errors in parentheses 


\section{Table 4: Wind Power Capacity Tobit Marginal Effects - Incentive Revenue}

\begin{tabular}{|c|c|c|c|c|c|}
\hline $\begin{array}{l}\text { Dependent Variable } \\
\text { Capacity additions }(\mathrm{kW})\end{array}$ & $\begin{array}{c}\text { Full } \\
1996-2010\end{array}$ & $\begin{array}{c}\text { StrEG } \\
1996-1999\end{array}$ & $\begin{array}{c}\text { EEG I } \\
2000-2004\end{array}$ & $\begin{array}{c}\text { EEG II } \\
2005-2010\end{array}$ & $\begin{array}{c}\text { EEG } \\
2000-2010\end{array}$ \\
\hline Lag capacity additions $(\mathrm{kW})$ & $\begin{array}{c}0.111^{* * * *} \\
(0.01)\end{array}$ & $\begin{array}{c}0.192^{* * *} \\
(0.03)\end{array}$ & $\begin{array}{c}0.214^{* * *} \\
(0.03)\end{array}$ & $\begin{array}{l}0.0311 \\
(0.02)\end{array}$ & $\begin{array}{l}0.0937 * * * \\
\quad(0.02)\end{array}$ \\
\hline $\begin{array}{l}\text { Lag capacity additions squared } \\
\qquad\left(10^{3} \mathrm{~kW}^{2}\right)\end{array}$ & $\begin{array}{c}-0.000533^{* * *} \\
(0.00)\end{array}$ & $\begin{array}{c}-0.00247^{* * * *} \\
(0.00)\end{array}$ & $\begin{array}{c}-0.00144^{* * * *} \\
(0.00)\end{array}$ & $\begin{array}{l}-0.0000501 \\
\quad(0.00)\end{array}$ & $\begin{array}{c}-0.000509^{* *} \\
(0.00)\end{array}$ \\
\hline $\begin{array}{l}\text { Incentive revenue } \\
\qquad\left(€ / \mathrm{m}^{2}, 7 \% \text { discount }\right)\end{array}$ & $\begin{array}{c}12.71^{* * * *} \\
(1.35)\end{array}$ & $\begin{array}{c}3.361^{* * *} \\
(0.65)\end{array}$ & $\begin{array}{c}14.09 * * * \\
(2.04)\end{array}$ & $\begin{array}{c}14.25^{* * * *} \\
(2.38)\end{array}$ & $\begin{array}{c}16.11^{* * *} \\
(1.92)\end{array}$ \\
\hline Ineligible for incentive $(0 / 1)$ & $\begin{array}{c}248.4 \\
(527.16)\end{array}$ & & & $\begin{array}{c}-435.4 \\
(788.14)\end{array}$ & $\begin{array}{c}773.5 \\
(722.96)\end{array}$ \\
\hline Area $\left(\mathrm{km}^{2}\right)$ & $\begin{array}{c}2.435^{* * *} \\
(0.29)\end{array}$ & $\begin{array}{c}0.689^{* * *} \\
(0.13)\end{array}$ & $\begin{array}{c}2.960 * * * \\
(0.43)\end{array}$ & $\begin{array}{c}2.919 * * * \\
(0.43)\end{array}$ & $\begin{array}{c}3.095^{* * * *} \\
(0.39)\end{array}$ \\
\hline Grid density $\left(\mathrm{km} / \mathrm{km}^{2}\right)$ & $\begin{array}{l}1.345 \\
(1.64)\end{array}$ & $\begin{array}{l}1.589 * \\
(0.68)\end{array}$ & $\begin{array}{l}-5.235 \\
(5.83)\end{array}$ & $\begin{array}{l}1.080 \\
(3.10)\end{array}$ & $\begin{array}{l}-0.777 \\
(3.30)\end{array}$ \\
\hline GDP (billion $€$ ) & $\begin{array}{l}89.81 * * \\
(27.96)\end{array}$ & $\begin{array}{c}85.86^{* * * *} \\
(14.35)\end{array}$ & $\begin{array}{c}153.5^{* * *} \\
(44.87)\end{array}$ & $\begin{array}{c}69.43 \\
(38.84)\end{array}$ & $\begin{array}{l}97.60 * * \\
(37.10)\end{array}$ \\
\hline Population per $\mathrm{km}^{2}$ & $\begin{array}{c}-1.467^{* * * *} \\
(0.43)\end{array}$ & $\begin{array}{c}-0.715^{* *} \\
(0.23)\end{array}$ & $\begin{array}{c}-2.047 * * \\
(0.69)\end{array}$ & $\begin{array}{l}-1.238 \\
(0.65)\end{array}$ & $\begin{array}{c}-1.705^{* *} \\
(0.59)\end{array}$ \\
\hline Land value $\left(€ / \mathrm{m}^{2}\right)$ & $\begin{array}{c}-8.674^{* * * *} \\
(2.28)\end{array}$ & $\begin{array}{c}-5.856^{* * *} \\
(1.49)\end{array}$ & $\begin{array}{c}-18.43^{* * * *} \\
(4.24)\end{array}$ & $\begin{array}{c}-8.799^{*} \\
(3.96)\end{array}$ & $\begin{array}{c}-11.40^{* * *} \\
(3.16)\end{array}$ \\
\hline Green Party votes (\%, state) & $\begin{array}{l}-72.41 \\
(45.83)\end{array}$ & $\begin{array}{l}131.2^{* *} \\
(47.73)\end{array}$ & $\begin{array}{c}212.8 \\
(123.99)\end{array}$ & $\begin{array}{l}-245.1^{* *} \\
(82.31)\end{array}$ & $\begin{array}{l}-74.02 \\
(67.68)\end{array}$ \\
\hline Green Party votes ( $\%$, federal) & $\begin{array}{c}85.41 \\
(63.93)\end{array}$ & $\begin{array}{c}-325.5^{* * * *} \\
(81.98)\end{array}$ & $\begin{array}{c}-194.5 \\
(140.61)\end{array}$ & $\begin{array}{c}250.5^{*} \\
(110.71)\end{array}$ & $\begin{array}{c}90.26 \\
(87.99)\end{array}$ \\
\hline Time index & $\begin{array}{c}1845.7^{* * *} \\
(271.77)\end{array}$ & $\begin{array}{c}546.8 \\
(3028.33)\end{array}$ & $\begin{array}{c}24081.2 \\
(16528.32)\end{array}$ & $\begin{array}{c}27573.2 \\
(19978.93)\end{array}$ & $\begin{array}{c}3648.2^{*} \\
(1515.00)\end{array}$ \\
\hline Time index squared & $\begin{array}{c}-164.6^{* * * *} \\
(32.67)\end{array}$ & $\begin{array}{c}-212.7 \\
(907.27)\end{array}$ & $\begin{array}{c}-2485.1 \\
(2102.36)\end{array}$ & $\begin{array}{c}-2070.1 \\
(1490.19)\end{array}$ & $\begin{array}{l}-344.1^{*} \\
(144.55)\end{array}$ \\
\hline Time index cubed & $\begin{array}{c}4.164^{* * *} \\
(1.19)\end{array}$ & $\begin{array}{c}32.84 \\
(86.02)\end{array}$ & $\begin{array}{c}79.50 \\
(87.73)\end{array}$ & $\begin{array}{c}50.69 \\
(36.73)\end{array}$ & $\begin{array}{l}9.625^{*} \\
(4.41)\end{array}$ \\
\hline Counties & 402 & 402 & 402 & 402 & 402 \\
\hline Uncensored observations & 2,173 & 501 & 884 & 788 & 1,672 \\
\hline Observations & 6,030 & 1,608 & 2,010 & 2,412 & 4,422 \\
\hline
\end{tabular}

$* \mathrm{p}<0.10, * * \mathrm{p}<0.05, * * * \mathrm{p}<0.01$, standard errors in parentheses 
Table 5: Wind Power Capacity Tobit Marginal Effects - Undiscounted Incentive Revenue

\begin{tabular}{|c|c|c|c|c|c|}
\hline Dependent Variable: & Full & StrEG & EEG I & EEG II & EEG \\
\hline Capacity additions (kW) & $1996-2010$ & 1996-1999 & $2000-2004$ & $2005-2010$ & $2000-2010$ \\
\hline Lag capacity additions $(\mathrm{kW})$ & $\begin{array}{c}0.111^{* * *} \\
(0.01)\end{array}$ & $\begin{array}{c}0.192^{* * *} \\
(0.03)\end{array}$ & $\begin{array}{c}0.214^{* * *} \\
(0.03)\end{array}$ & $\begin{array}{c}0.0313 \\
(0.02)\end{array}$ & $\begin{array}{c}0.0936^{* * *} \\
(0.02)\end{array}$ \\
\hline $\begin{array}{l}\text { Lag capacity additions squared } \\
\qquad\left(10^{3} \mathrm{~kW}^{2}\right)\end{array}$ & $\begin{array}{c}-0.000527^{* * *} \\
(0.00)\end{array}$ & $\begin{array}{c}-0.00247^{* * *} \\
(0.00)\end{array}$ & $\begin{array}{c}-0.00144^{* * *} \\
(0.00)\end{array}$ & $\begin{array}{c}-0.0000452 \\
(0.00)\end{array}$ & $\begin{array}{c}-0.000504^{* *} \\
(0.00)\end{array}$ \\
\hline $\begin{array}{l}\text { Incentive revenue } \\
\qquad\left(€ / \mathrm{m}^{2}, 0 \% \text { discount }\right)\end{array}$ & $\begin{array}{c}6.558^{* * *} \\
(0.71)\end{array}$ & $\begin{array}{c}1.780^{* * * *} \\
(0.35)\end{array}$ & $\begin{array}{c}7.610^{* * * *} \\
(1.11)\end{array}$ & $\begin{array}{c}7.538^{* * * *} \\
(1.30)\end{array}$ & $\begin{array}{c}8.572^{* * * *} \\
(1.04)\end{array}$ \\
\hline Ineligible for incentive $(0 / 1)$ & $\begin{array}{c}207.5 \\
(522.52)\end{array}$ & & & $\begin{array}{c}-458.9 \\
(791.47)\end{array}$ & $\begin{array}{c}763.3 \\
(722.87)\end{array}$ \\
\hline Area $\left(\mathrm{km}^{2}\right)$ & $\begin{array}{c}2.448^{* * * *} \\
(0.29)\end{array}$ & $\begin{array}{c}0.689 * * * \\
(0.13)\end{array}$ & $\begin{array}{c}2.953^{* * * *} \\
(0.43)\end{array}$ & $\begin{array}{c}2.929 * * * \\
(0.43)\end{array}$ & $\begin{array}{c}3.102^{* * * *} \\
(0.39)\end{array}$ \\
\hline Grid density $\left(\mathrm{km} / \mathrm{km}^{2}\right)$ & $\begin{array}{l}1.321 \\
(1.64)\end{array}$ & $\begin{array}{l}1.589^{*} \\
(0.68)\end{array}$ & $\begin{array}{l}-5.256 \\
(5.83)\end{array}$ & $\begin{array}{l}1.066 \\
(3.11)\end{array}$ & $\begin{array}{l}-0.790 \\
(3.31)\end{array}$ \\
\hline GDP (billion $€$ ) & $\begin{array}{c}89.14^{* *} \\
(27.96)\end{array}$ & $\begin{array}{c}85.86^{* * * *} \\
(14.35)\end{array}$ & $\begin{array}{c}152.6^{* * * *} \\
(44.92)\end{array}$ & $\begin{array}{c}68.56 \\
(38.95)\end{array}$ & $\begin{array}{c}96.65 * * \\
(37.19)\end{array}$ \\
\hline Population per $\mathrm{km}^{2}$ & $\begin{array}{c}-1.470^{* * *} \\
(0.43)\end{array}$ & $\begin{array}{c}-0.715^{* *} \\
(0.23)\end{array}$ & $\begin{array}{c}-2.050^{* *} \\
(0.69)\end{array}$ & $\begin{array}{l}-1.244 \\
(0.65)\end{array}$ & $\begin{array}{c}-1.711^{* *} \\
(0.59)\end{array}$ \\
\hline Land value $\left(€ / \mathrm{m}^{2}\right)$ & $\begin{array}{c}-8.905^{* * *} \\
(2.28)\end{array}$ & $\begin{array}{c}-5.856^{* * * *} \\
(1.49)\end{array}$ & $\begin{array}{c}-18.38^{* * *} \\
(4.25)\end{array}$ & $\begin{array}{c}-8.996^{*} \\
(3.97)\end{array}$ & $\begin{array}{c}-11.51^{* * * *} \\
(3.16)\end{array}$ \\
\hline Green Party votes (\%, state) & $\begin{array}{l}-72.90 \\
(45.86)\end{array}$ & $\begin{array}{c}131.2^{* *} \\
(47.73)\end{array}$ & $\begin{array}{c}214.1 \\
(124.00)\end{array}$ & $\begin{array}{c}-244.7^{* * *} \\
(82.47)\end{array}$ & $\begin{array}{l}-73.10 \\
(67.73)\end{array}$ \\
\hline Green Party votes (\%, federal) & $\begin{array}{c}92.82 \\
(63.93)\end{array}$ & $\begin{array}{c}-325.5^{* * * *} \\
(81.98)\end{array}$ & $\begin{array}{c}-194.5 \\
(140.64)\end{array}$ & $\begin{array}{c}259.1^{*} \\
(110.86)\end{array}$ & $\begin{array}{c}95.31 \\
(88.05)\end{array}$ \\
\hline Time index & $\begin{array}{c}1866.3^{* * *} \\
(272.31)\end{array}$ & $\begin{array}{c}546.8 \\
(3028.33)\end{array}$ & $\begin{array}{c}24091.9 \\
(16525.52)\end{array}$ & $\begin{array}{c}27496.8 \\
(20018.77)\end{array}$ & $\begin{array}{c}3608.3^{*} \\
(1518.53)\end{array}$ \\
\hline Time index squared & $\begin{array}{c}-166.9^{* * *} \\
(32.72)\end{array}$ & $\begin{array}{c}-212.7 \\
(907.27)\end{array}$ & $\begin{array}{c}-2487.0 \\
(2102.01)\end{array}$ & $\begin{array}{c}-2064.1 \\
(1493.04)\end{array}$ & $\begin{array}{l}-340.2^{*} \\
(144.94)\end{array}$ \\
\hline Time index cubed & $\begin{array}{c}4.247^{* * *} \\
(1.19)\end{array}$ & $\begin{array}{c}32.84 \\
(86.02)\end{array}$ & $\begin{array}{c}79.60 \\
(87.72)\end{array}$ & $\begin{array}{c}50.53 \\
(36.80)\end{array}$ & $\begin{array}{c}9.507^{*} \\
(4.42)\end{array}$ \\
\hline Counties & 402 & 402 & 402 & 402 & 402 \\
\hline Uncensored observations & 2,173 & 501 & 884 & 788 & 1,672 \\
\hline Observations & 6,030 & 1,608 & 2,010 & 2,412 & 4,422 \\
\hline
\end{tabular}

$* \mathrm{p}<0.10, * * \mathrm{p}<0.05, * * * \mathrm{p}<0.01$, standard errors in parentheses

\subsection{Analysis of Counterfactual Scenarios: Uniform Incentives}

In this section we explore the effect of a uniform incentive on wind power development across counties. Beginning with the EEG in 2000, the federal incentive for wind power varied according to wind power potential with less windy sites receiving a higher FIT rate than more windy sites. This translates into incentive revenue increasing linearly with windpower potential but then gradually flattening out until the maximum incentive is reached. Here, we estimate capacity additions over time under a different hypothetical FIT regime - a uniform national incentive that does not vary with wind power potential. 
Three different hypothetical FIT levels are considered (Table 6). In all three cases, all locations are presumed eligible to receive the incentive, in contrast to the EEG, which excludes locations with output less than $60 \%$ of reference output after August 1, 2004 14 Under the EEG, the 5-year period with the higher initial incentive is extended depending on the location's windiness, such that the 20 -year average FIT varies across counties. The high, medium and low counterfactual incentives are calculated as follows (Table 6). The low FIT is equivalent to the 20 year average of the minimum FIT achieved under the EEG, namely 5 years of the initial FIT and 15 years of the base FIT. The high FIT is calculated as the average across counties of the realized 20-year-average EEG FIT. The medium FIT equals about 1.35 times the low FIT. Its level is chosen such that the total predicted installed capacity under the EEG and the medium FIT are equal to allow for better comparison. We also include the case when no FIT subsidies are offered.

Table 6: Hypothetical Average Feed-In Tariffs (€-cent/kWh)

\begin{tabular}{lllllll}
\hline \hline \multirow{2}{*}{ Year } & \multicolumn{2}{c}{ EEG incentive } & & \multicolumn{3}{c}{ Uniform incentive } \\
\cline { 2 - 3 } & Min & Max & & High & Medium & Low \\
\hline 2000 & 6.96 & 9.10 & & 9.05 & 9.32 & 6.92 \\
2001 & 6.96 & 9.10 & & 9.05 & 9.32 & 6.92 \\
2002 & 6.96 & 9.10 & & 9.05 & 9.32 & 6.92 \\
2003 & 6.96 & 9.10 & & 9.05 & 9.32 & 6.92 \\
2004 & 6.96 & 9.10 & & 9.05 & 9.32 & 6.92 \\
2005 & 6.22 & 8.53 & & 8.48 & 8.32 & 6.17 \\
2006 & 6.09 & 8.36 & & 8.31 & 8.15 & 6.05 \\
2007 & 5.97 & 8.19 & & 8.14 & 7.98 & 5.93 \\
2008 & 5.85 & 8.03 & & 7.98 & 7.83 & 5.81 \\
2009 & 6.25 & 9.70 & & 9.62 & 8.34 & 6.19 \\
2010 & 6.19 & 9.60 & 9.53 & 8.25 & 6.13 \\
\hline \hline
\end{tabular}

A priori, it is unclear whether the uniform incentive or the wind-dependent EEG incentive achieves greater wind power output per euro $(\mathrm{kWh} / €)$. Presumably, the EEG will achieve lower wind power output per installed turbine, since it offers a reduced incentive in very windy areas. However, the uniform incentive may overspend on subsidies for wind turbines in high-wind areas, which would experience development even at lower incentive levels. Thus, while the uniform incentive is expected to outperform the EEG in terms of wind power output per installed turbine, the relative standings in terms of wind power output per euro are unclear.

The impact of the incentive structure on emission reductions per euro (CO2 kg/€) is also uncertain. This depends in part on how well the different incentive structures perform in terms on $\mathrm{kWh} / €$. However, it also depends on the degree of correlation between windiness and regional emissions. If windiness and regional emissions are negatively correlated net of other factors that affect a location's suitability, the EEG could achieve greater reductions in emissions per euro spent than a uniform incentive.

\footnotetext{
${ }^{14}$ In our county-level annual analysis, those locations are captured as counties with potential output less than 50\% of reference output after December 31, 2004.
} 
Annual additions to installed capacity are predicted under the EEG as well as the high, medium, and low uniform incentives. Since the level of the uniform incentives are contained within the bounds of actual EEG incentive levels experienced across counties, the prediction can be considered in-sample. It is of course expected that predicted and actual capacity additions under the EEG diverge to some extent. Indeed, the EEG prediction using actual EEG capacity for the lag capacity variable does well. Actual EEG installed capacity and output reaches $23.34 \mathrm{GW}$ and 229.5 TWh, while we predict $21.63 \mathrm{GW}$ and $217.2 \mathrm{TWh}$.

However, we must focus on the case where predicted capacities are used as lag capacities in the following year to avoid biasing the predicted distribution towards the actual distribution. As 10 years of capacity additions are predicted in this way, errors compound and the predicted EEG capacity additions diverge quite substantially from actual capacity additions towards 2010 . With this prediction method, total predicted capacity reaches $8.806 \mathrm{GW}$ compared to the actual capacity of $23.34 \mathrm{GW}$. However, we are more interested in comparing predicted capacity additions across the different incentive structures than in the absolute level of predicted capacity additions. The divergence between predicted and actual EEG capacity additions is therefore less of an issue.

Table 7 presents the results of the counterfactual analysis, showing the total cost, installed capacity, expected wind power output, and avoided carbon dioxide emissions for each of the scenarios considered. In addition, measures of efficiency are computed, including output per euro spent $(\mathrm{kWh} / €)$ and avoided emissions per euro spent $\left(\mathrm{CO}_{2} \mathrm{~kg} / €\right)$. We estimate that about $0.538 \mathrm{GW}$ or $6 \%$ of predicted capacity would have been installed even if there had been no FIT incentive, mainly in northern Germany. The uniform low incentive achieves the greatest wind power output and $\mathrm{CO}_{2}$ emission reductions per euro spent at $15.38 \mathrm{kWh} / €$ and $4.658 \mathrm{~kg} / €$. This result is not surprising. Higher levels of efficiency are of course achieved at lower total levels of wind power development, as prime locations are developed before less suitable locations.

The medium incentive can be more directly compared with the EEG prediction. The incentive level is set at about 1.35 times the low incentive such that the total installed capacity under the medium uniform incentive matches that of the EEG prediction at $8.806 \mathrm{GW}$. For the same amount of installed capacity, wind power output under the EEG (86.65 TWh) is lower than under the uniform incentive (88.93TWh). However, at 7.828 billion euros, the uniform incentive is more costly than the EEG at 7.554 billion euros, since the EEG reduces costs by recognizing that windy areas require less support to make an attractive investment. Overall, the EEG performs slightly better than the equivalent uniform incentive in terms of output per euro (11.47 kWh/€compared with $11.36 \mathrm{kWh} / €)$ and emission reductions per euro (3.596 $\mathrm{kg} / €$ compared with $3.469 \mathrm{~kg} / €)$. However, the improvement is marginal at $1 \%$ for output per euro and $3.7 \%$ for emission reductions per euro.

The EEG would likely perform even better than a uniform incentive if transmission congestion were taken into account. High concentrations of wind power in particular areas and transmission constraints mean that not all of the wind power can be transported to electricity demand areas. Compared with a uniform incentive, the EEG results in a more distributed arrangement of wind power plants across the transmission grid and thus lower levels of congestion and higher levels of emission reductions. The 3.7\% improvement over a uniform incentive in terms of emission reductions per euro would likely increase if transmission congestion is considered. 


\section{Table 7: Relative Efficiency of the EEG and Uniform Incentives}

\begin{tabular}{lcccccc}
\hline \hline Scenario & Capacity & Output & Cost & $\begin{array}{c}\text { Avoided CO2 } \\
\text { emissions } \\
\text { (million ton })\end{array}$ & $\begin{array}{c}\text { Efficiency } \\
\text { Output } \\
(\mathrm{kWh} / €)^{*}\end{array}$ & $\begin{array}{c}\text { Abatement } \\
\left(\mathrm{CO}_{2} \mathrm{~kg} / €\right)^{*}\end{array}$ \\
\hline Predicted EEG & 8.806 & 86.65 & 7.554 & 27.17 & 11.47 & 3.596 \\
\hline Medium incentive & 8.806 & 88.93 & 7.828 & 27.16 & 11.36 & 3.469 \\
High incentive & 9.105 & 92.13 & 8.218 & 28.14 & 11.21 & 3.425 \\
Low incentive & 4.972 & 49.80 & 3.255 & 14.92 & 15.30 & 4.584 \\
No incentive & 0.538 & 5.045 & 0 & 1.416 & & \\
\hline \hline
\end{tabular}

The cost and efficiency measures are undiscounted values. Due to the time value of money, a better estimate of EEG cost would involve discounting, which could not be implemented in this calibration exercise. Thus, it is appropriate to compare the relative efficiency of the different policy scenarios presented in this paper, but it does not make sense to compare the amount of avoided carbon emissions per euro with other abatement technologies. These values do, however, give an upper bound, since discounting would only lower the cost. The high incentive is the county-average EEG incentive by year, while the low incentive assumes the lowest possible EEG incentive (5 years higher initial incentive and 15 years lower base incentive). The medium incentive is about 1.35 times the low incentive.

The counterfactual analysis demonstrates that a uniform incentive would have resulted in a different distribution of wind power plants across counties. Graph 5 shows the difference in predicted cumulative capacity in 2010 between the EEG and uniform medium incentive. Under the uniform incentive, significantly more development occurs in the northern coastal counties with the greatest wind power potential (marked as white in the graph). The winddependent incentive of the EEG leads to relatively greater development in all other counties (shaded blue), thus resulting in a more distributed arrangement of wind power plants across Germany. However, the differences in installed capacities in non-Northern counties between the two types of incentives is relatively small.

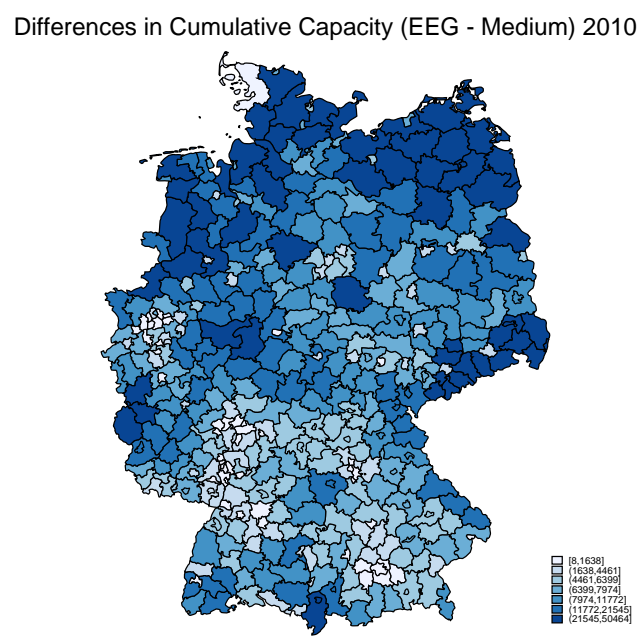

\section{Figure 5: Differences in Predicted Cumulative Capacity (kW) in 2010 (EEG - Medium Incentive)*}

\footnotetext{
* More wind power capacity is installed in the northern coastal counties under the uniform medium incentive than under the EEG, as indicated by the white color. All other counties (shaded blue) experience greater wind power development under the EEG.
} 
While a uniform incentive means that wind power plant revenue increases linearly with windpower potential, the wind-dependent EEG incentive translates into a flattening of the revenue curve at windpower potential output levels of $150 \%$ or greater of reference output. Under the EEG, mid- to high-wind locations have equal revenue-earning potential, but lowwind sites are still less profitable than high-wind sites. Thus, for both the EEG and the uniform incentive, high-wind locations are developed first, with development shifting south in the late 2000s. Figure 6a shows how additions to capacity occurred mainly in the north in 2003 but moved further south by 2010 (Figure 6b), resulting in a distribution of cumulative capacity not dissimilar to that under the EEG.

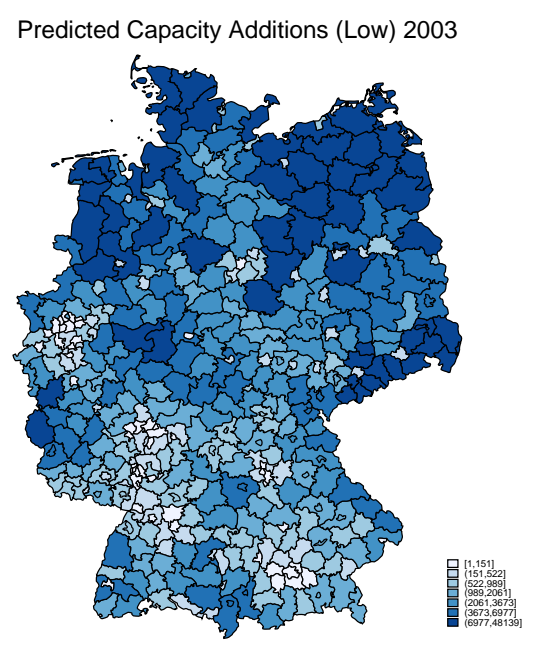

(a) Predicted Addition 2003

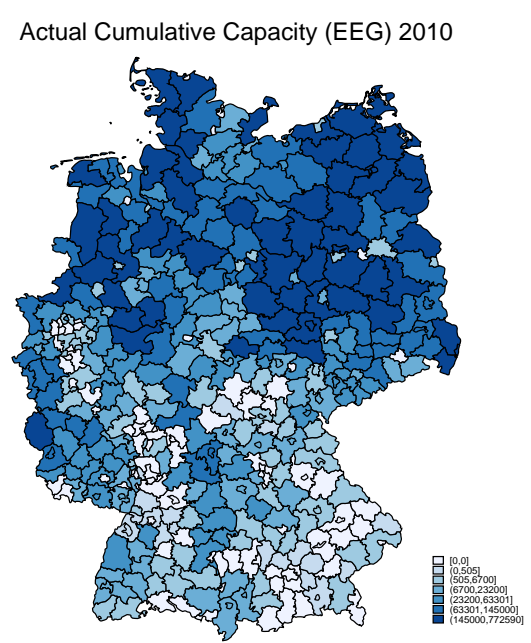

(c) Actual Cumulative 2010

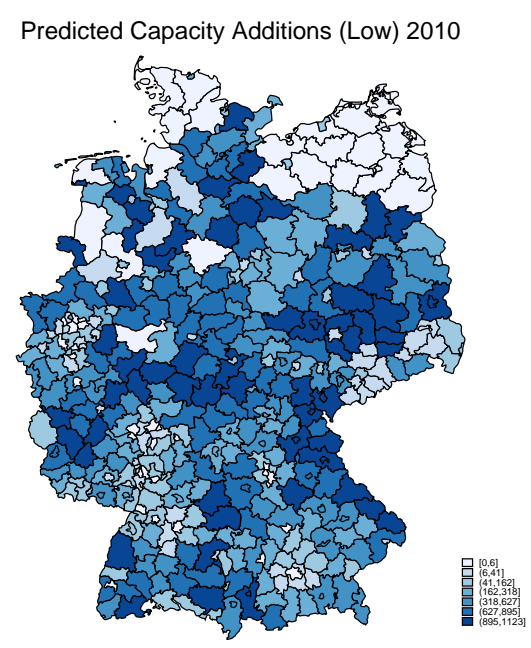

(b) Predicted Addition 2010

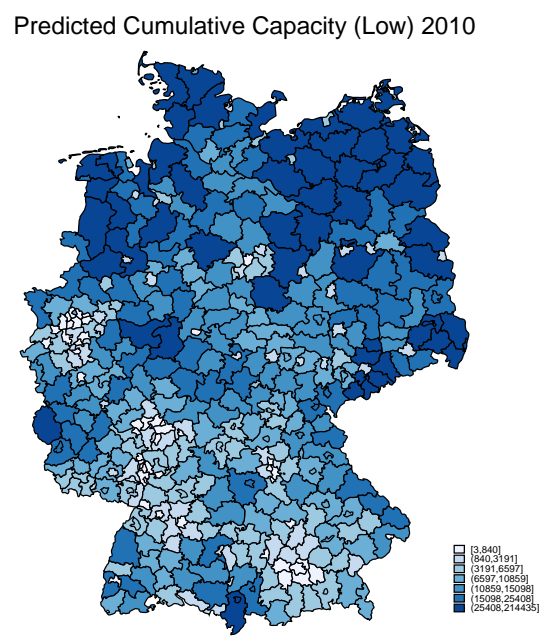

(d) Predicted Cumulative 2010

Figure 6: Cumulative Installed Wind Power Capacity under the EEG and Low Uniform Incentive 


\section{Conclusion}

Almost a quarter century has passed since feed-in tariffs for renewable power were first introduced in Germany in 1991. The impact on the power sector has been profound with renewable power supplying $24 \%$ of electricity in 2013 [DESTATIS, 2014]. Compared to other countries, the financial incentives for renewable power in Germany are quite generous. In addition, renewable power benefits from guaranteed access to the transmission grid.

One of the main results concerns the relative importance of transmission grid infrastructure for developers investing in wind power capacity. After 2000 the cost of transmission system upgrades was shifted from renewable power developers to grid operators, such that scarcity in transmission capacity was no longer signaled to developers. Correspondingly, we find that grid infrastructure does not play a significant role in the location decision of developers after the regulatory change in 2000 . While the regulatory change in 2000 benefitted wind power developers, the lack of a location signal for scarcity in transmission capacity has likely resulted in a distribution of wind power plants that makes suboptimal use of the existing grid infrastructure. Signaling scarcity in transmission capacity might have diminished the current need for investment in new transmission corridors.

We find that the feed-in tariff offered since 1991 is a significant driver of wind power development. A $1 €$-cent/kWh increase in the feed-in tariff would raise annual additions to installed wind by capacity at the national level by around $764 \mathrm{MW}$. The effect of the feed-in tariff is stronger towards the end of the study period in $2005-2010$, when a $1 €$-cent $/ \mathrm{kWh}$ increase would cause annual capacity additions at the national level to increase by 1,528 MW. We also find a significant effect of a 2004 change in the law that made locations below a certain threshold of wind power potential ineligible to receive the feed-in tariff. Wind power investment drops significantly at the ineligibility cutoff.

A counterfactual analysis shows that wind power investment occurs to a lesser extent in high-wind areas under the EEG than under a hypothetical uniform incentive that does not vary according to wind power potential. While the uniform incentive achieves a higher total output per capacity ratio than the EEG, the cost under the EEG is lower, though minimally so. Thus, the EEG goal of cost containment is achieved without too large a sacrifice in output per capacity. The EEG achieves slightly greater efficiency in terms of output per euro than a hypothetical uniform incentive.

The ultimate goal of any incentive for renewable power is to reduce power sector emissions. Pricing emissions is the first best way of achieving this goal, because subsidies for renewable power do not take into account that the abatement potential of a renewable power plant varies depending on its location within the grid and on the timing of power output. At each location within the grid and each point in time, a renewable power plant's output substitutes for output from a different set of conventional power plants with differing emission rates.

As the EEG provides, compared with a uniform incentive, a relatively greater incentive for investment in renewable power in the East, South, and Ruhr area of Germany, which happens to be where average power sector emissions are greater, the EEG may have contributed to a greater reduction in emissions than a uniform incentive. We find that the EEG reduces power sector emissions at about 3.7\% lower cost than a uniform incentive, though this result rests on the simplifying assumption that wind power substitutes equally for all types of 
power (coal, natural gas, hydro) in each region. The actual impact of wind power on emissions requires modeling the redispatch of power, thus using marginal rather than average emission rates.

Linking the level of the feed-in tariff to wind power potential under the EEG reduced the cost of the subsidy, relieved transmission congestion, and increased emission reductions relative to a uniform incentive. These three goals could have been achieved more efficiently. A feed-in tariff system that would have taken into account transmission constraints and the location- and time-varying nature of the abatement potential of renewable power plants would have achieved emission reductions at lower cost than the EEG. 


\section{REFERENCES}

BDEW. Grid data. Bundesverband der Energie und Wasserwirtschaft, German Association of Energy and Water Industries, 2013.

Andreas Berchem. Ökostrom: Das Unterschätzte Gesetz. Die Zeit, 2006. URL http://www. zeit.de/online/2006/39/EEG/komplettansicht.

BMU. Transformation of the energy system. Federal Ministry for the Environment, Nature Conservation and Nuclear Safety, 2013. URL http://www.bmu. de/en/topics/climate-energy/transformation-of-the-energy-system/ general-information/.

BMWi. Stromerzeugungskapazitäten, Bruttostromerzeugung und Bruttostromverbrauch. Federal Ministry of Economics and Technology, Bundesministerium für Wirtschaft und Technologie (BMWi), 2013.

BNA. List of power plants. Federal Network Agency, Bundesnetzagentur (BNA), 2014.

BNEF. China was world's largest wind market in 2012. Bloomberg New Energy Finance, 2013. URL http://about.bnef.com/press-releases/ china-was-worlds-largest-wind-market-in-2012/.

BPB. Ausbau des Stromnetzes: Notwendigkeit der Energiewende. Doessier Energiepolitik, Bundeszentrale für politische Bildung, 2013.

Uwe Büsgen and Wolfhart Dürrschmidt. The expansion of electricity generation from renewable energies in Germany: A review based on the renewable energy sources act progress report 2007 and the new German feed-in legislation. Energy Policy, 37(7):2536 - 2545, 2009.

DESTATIS. Gross electricity production in Germany from 2011 to 2013. German Federal Statistical Office (DESTATIS), 2014.

Jochen Diekmann, Dietmar Edler, Manfred Horn, Claudia Kemfert, Wolfram Krewitt, Ulrike Lehr, Michael Nast, Joachim Nitsch, Julita Link, Ole Langniß, Günther Frey, Juri Horst, and Uwe Leprich. Analyse und Bewertung der Wirkungen des Erneuerbare-EnergienGesetzes (EEG) aus gesamtwirtschaftlicher Sicht. Forschungsvorhaben des Bundesministeriums für Umwelt, Natuerschutz und Reaktorsicherheit, 2008.

DWD. Data on wind power potential, Daten zur Windkraftnutzungseignung. German Weather Service (Deutscher Wetterdienst, DWD), Federal Ministry of Transport, Building and Urban Development, 2013.

EC. Energy markets in the European Union in 2011. European Commission, 2012.

EEG/KWK-G. EEG-Anlagenstammdaten, 2013. URL http:\www.eeg-kwk.net/de/ Anlagenstammdaten.htm. 
EIA. Electric power monthly: August. Energy Information Administration, US Department of Energy, 2013.

EWEA. The economics of wind energy. European Wind Energy Association, 2009.

Manuel Frondel, Nolan Ritter, Christoph M. Schmidt, and Colin Vance. Economic impacts from the promotion of renewable energy technologies: The German experience. Energy Policy, 38(8):4048 - 4056, 2010.

FSSO. Regional database Germany. Federal and State Statistical Offices, 2013. URL Www. regionalstatistik.de.

Claudia Hitaj. Wind power development in the United States. Journal of Environmental Economics and Management, 65:394-410, 2013.

Claudia Hitaj. Location matters: The impact of renewable power on transmission congestion and emissions. unpublished manuscript, 2014.

Uwe Leprich, Günther Frey, and Juri Horst. Analyse und Bewertung der Wirkungen des EEG im bundesdeutschen Stromsektor. in Analyse und Bewertung der Wirkungen des Erneuerbare-Energien-Gesetzes (EEG) aus gesamtwirtschaftlicher Sicht, Forschungsvorhaben des Bundesministeriums für Umwelt, Natuerschutz und Reaktorsicherheit, 2008.

Daniel Lübbert. CO2-Bilanzen verschiedener Energieträger im Vergleich. Deutscher Bundestag, 2007.

Benjamin R. Phillips and Richard S. Middleton. SimWIND: A geospatial infrastructure model for optimizing wind power generation and transmission. Energy Policy, 43:291 - 302, 2012.

Karen Smith Stegen and Matthias Seel. The winds of change: How wind firms assess Germany's energy transition. Energy Policy, 61:1481-1489, 2013.

James Tobin. Estimation of relationships for limited dependent variables. Econometrica, 26: 24-36, 1958.

Thure Traber and Claudia Kemfert. Impacts of German support for renewable energy on electricity prices, emissions, and firms. The Energy Journal, 30:155-178, 2009.

Thure Traber and Claudia Kemfert. Gone with the wind? - electricity market prices and incentives to invest in thermal power plants under increasing wind energy supply. Energy Economics, 33:249-256, 2011.

H. Weigt and C. von Hirschhausen. Price formation and market power in the German wholesale electricity market in 2006. Energy Policy, 36:4227-4234, 2008. 


\section{Appendix A: Control areas}

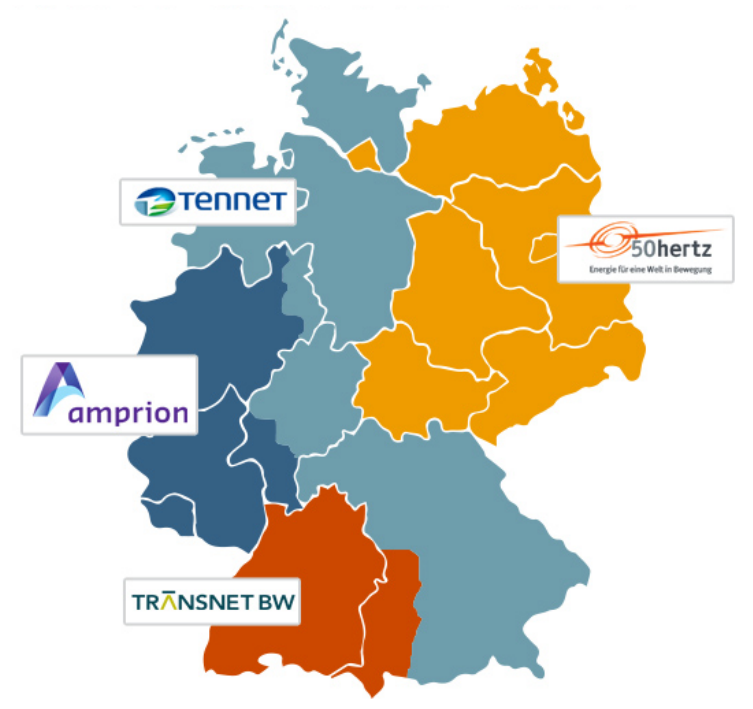

Figure 7: Control areas of the four transmission system operators BPB [2013]

\section{Appendix B: Power Plant Emission Rates by State}

\section{Table 8: Conventional Power Plant Emission Rates by State}

\begin{tabular}{|c|c|c|c|c|c|}
\hline \multirow[t]{3}{*}{ State } & \multicolumn{4}{|c|}{ Generating Capacity (\%) } & \multirow{3}{*}{$\begin{array}{c}\text { Emissions } \\
(\mathrm{kg} \mathrm{CO} 2-\mathrm{eq} / \mathrm{kWh})\end{array}$} \\
\hline & Lignite Coal & Hard Coal & Oil & Natural & \\
\hline & & & & Gas & \\
\hline Baden-Württemberg & 0 & 23.941 & 3.978 & 6.227 & 33.382 \\
\hline Bavaria & 0 & 3.228 & 3.781 & 16.908 & 17.673 \\
\hline Berlin & 6.540 & 30.987 & 13.041 & 44.124 & 81.356 \\
\hline Brandenburg & 31.321 & 0 & 2.369 & 6.008 & 44.478 \\
\hline Bremen & 0 & 57.287 & 5.768 & 11.117 & 74.118 \\
\hline Hamburg & 0 & 37.072 & 7.262 & 27.378 & 64.023 \\
\hline Hesse & 0.559 & 16.734 & 0.414 & 24.729 & 34.957 \\
\hline Mecklenburg-Vorpommern & 0 & 11.976 & 0 & 6.763 & 17.262 \\
\hline Lower Saxony & 1.619 & 9.889 & 0.270 & 17.503 & 24.114 \\
\hline North Rhine-Westphalia & 26.015 & 28.971 & 1.219 & 18.820 & 76.417 \\
\hline Rhineland-Palatinate & 0 & 0.224 & 0 & 30.145 & 19.535 \\
\hline Saarland & 0 & 71.362 & 0 & 5.416 & 80.538 \\
\hline Saxony & 48.842 & 0 & 0.192 & 6.570 & 64.452 \\
\hline Saxony-Anhalt & 16.582 & 0 & 3.412 & 11.022 & 30.486 \\
\hline Schleswig-Holstein & 0 & 8.920 & 6.461 & 0.240 & 15.538 \\
\hline Thuringia & 1.425 & 0 & 0 & 10.066 & 8.196 \\
\hline
\end{tabular}

The emissions rates for each state are calculated as the average emission rate of each generating technology weighted by the percent generating capacity of each technology. Data on capacity shares by state were obtained from BNA [2014]. The emissions rates in g CO2/kWH are 1,230 for lignite coal, 1,080 for hard coal, 890 for oil and 640 for natural gas [Lübbert, 2007]. 
Appendix C: OLS estimates as a robustness CheCK

Table 9: Wind Power Capacity Ordinary Least Squares

\begin{tabular}{|c|c|c|c|c|c|}
\hline Dependent Variable: & Full & StrEG & EEG I & EEG II & EEG \\
\hline Capacity additions (kW) & $1996-2010$ & 1996-1999 & $2000-2004$ & $2005-2010$ & $2000-2010$ \\
\hline \multirow[t]{2}{*}{ Lag capacity additions (kW) } & $0.601^{* * *}$ & $0.981^{* * * *}$ & $0.682^{* * * *}$ & $0.459 * * *$ & $0.569 * * *$ \\
\hline & $(0.02)$ & $(0.07)$ & $(0.04)$ & $(0.04)$ & $(0.03)$ \\
\hline Lag capacity additions squared & $-0.00198^{* * *}$ & $-0.0104 * * *$ & $-0.00291 * * *$ & -0.000713 & $-0.00172 * * *$ \\
\hline$\left(10^{3} \mathrm{~kW}^{2}\right)$ & $(0.00)$ & $(0.00)$ & $(0.00)$ & $(0.00)$ & $(0.00)$ \\
\hline Incentive revenue & $9.751^{* * *}$ & $4.679 * * *$ & $11.61^{* * *}$ & $9.610 * * *$ & $11.83^{* * *}$ \\
\hline$\left(€ / \mathrm{m}^{2}, 7 \%\right.$ discount $)$ & $(1.19)$ & $(1.30)$ & $(2.26)$ & $(2.37)$ & $(1.61)$ \\
\hline \multirow[t]{2}{*}{ Ineligible for incentive $(0 / 1)$} & 1022.5 & 0 & 0 & 760.5 & $1720.3^{* *}$ \\
\hline & $(554.10)$ & $(0.00)$ & $(0.00)$ & $(746.00)$ & $(645.87)$ \\
\hline \multirow[t]{2}{*}{ Area $\left(\mathrm{km}^{2}\right)$} & $3.450 * * *$ & $1.719 * * *$ & $4.698 * * *$ & $3.730 * * *$ & $4.122 * * *$ \\
\hline & $(0.24)$ & $(0.25)$ & $(0.48)$ & $(0.43)$ & $(0.32)$ \\
\hline \multirow[t]{2}{*}{ Grid density $\left(\mathrm{km} / \mathrm{km}^{2}\right)$} & 0.883 & 0.619 & 1.122 & 0.816 & 0.953 \\
\hline & $(1.21)$ & $(1.28)$ & $(2.35)$ & $(2.09)$ & $(1.57)$ \\
\hline \multirow[t]{2}{*}{ GDP (billion $€$ ) } & $-48.25^{*}$ & -17.15 & -56.61 & -60.32 & $-55.85^{*}$ \\
\hline & $(22.35)$ & $(25.76)$ & $(45.63)$ & $(36.27)$ & $(28.47)$ \\
\hline \multirow[t]{2}{*}{ Population per $\mathrm{km}^{2}$} & $1.067 * * *$ & $0.615^{*}$ & $1.471^{*}$ & $1.065^{*}$ & $1.222^{* *}$ \\
\hline & $(0.30)$ & $(0.31)$ & $(0.58)$ & $(0.53)$ & $(0.39)$ \\
\hline \multirow[t]{2}{*}{ Land value $\left(€ / \mathrm{m}^{2}\right)$} & 0.299 & 1.567 & 0.385 & -1.705 & -1.075 \\
\hline & $(1.87)$ & $(1.86)$ & $(3.52)$ & $(3.59)$ & $(2.51)$ \\
\hline \multirow[t]{2}{*}{ Green Party votes (\%, state) } & -72.95 & -0.0767 & 93.42 & $-227.0 *$ & -126.3 \\
\hline & $(65.44)$ & $(85.70)$ & $(153.23)$ & $(110.63)$ & $(88.83)$ \\
\hline \multirow[t]{2}{*}{ Green Party votes ( $\%$, federal) } & -1.727 & -96.40 & -187.8 & 228.2 & 63.64 \\
\hline & (81.93) & (130.17) & $(162.66)$ & (140.06) & $(104.50)$ \\
\hline \multirow[t]{2}{*}{ Time index } & $2019.9 * * *$ & 1285.5 & $56497.2^{*}$ & $-71520.8^{*}$ & 779.3 \\
\hline & $(447.58)$ & (6796.59) & $(26943.57)$ & (35870.92) & $(2508.15)$ \\
\hline \multirow[t]{2}{*}{ Time index squared } & $-194.7^{* * *}$ & -634.3 & -6577.0 & $5456.4^{*}$ & -86.48 \\
\hline & (55.13) & $(2042.02)$ & $(3422.43)$ & $(2675.31)$ & $(237.21)$ \\
\hline \multirow[t]{2}{*}{ Time index cubed } & $5.502^{* *}$ & 101.3 & 247.9 & $-137.8^{*}$ & 2.396 \\
\hline & $(2.02)$ & (194.10) & $(142.60)$ & $(65.96)$ & $(7.17)$ \\
\hline \multirow[t]{2}{*}{ Constant } & $-11404.6^{* * *}$ & -4472.0 & $-163981.6^{*}$ & 304365.3 & -8416.3 \\
\hline & $(1222.01)$ & (7131.02) & $(69569.56)$ & (159098.93) & $(8351.37)$ \\
\hline Counties & 402 & 402 & 402 & 402 & 402 \\
\hline Observations & 6,030 & 1,608 & 2,010 & 2,412 & 4,422 \\
\hline
\end{tabular}

$* \mathrm{p}<0.10, * * \mathrm{p}<0.05, * * * \mathrm{p}<0.01$, standard errors in parentheses 


\section{APPENDix D: Different INELigibility RATE}

Table 10: Wind Power Capacity Tobit Marginal Effects: Ineligibility at Less Than $60 \%$ of Reference Output

\begin{tabular}{|c|c|c|c|c|c|}
\hline Dependent Variable: & Full & StrEG & EEG I & EEG II & EEG \\
\hline Capacity additions (MW) & $1996-2010$ & 1996-1999 & 2000-2004 & $2005-2010$ & $2000-2010$ \\
\hline \multirow[t]{2}{*}{ Lag capacity additions (kW) } & $0.107^{* * *}$ & $0.192^{* * *}$ & $0.214^{* * *}$ & 0.0337 & $0.0897^{* * *}$ \\
\hline & $(0.01)$ & $(0.03)$ & $(0.03)$ & $(0.02)$ & $(0.02)$ \\
\hline Lag capacity additions squared & $-0.000508^{* * *}$ & $-0.00247^{* * *}$ & $-0.00144 * * *$ & -0.0000759 & $-0.000487 * *$ \\
\hline$\left(10^{3} \mathrm{~kW}^{2}\right)$ & $(0.00)$ & $(0.00)$ & $(0.00)$ & $(0.00)$ & $(0.00)$ \\
\hline Incentive revenue & $14.33^{* * *}$ & $3.361^{* * *}$ & $14.09^{* * * *}$ & $25.54^{* * *}$ & $18.52^{* * *}$ \\
\hline$\left(€ / \mathrm{m}^{2}, 7 \%\right.$ discount $)$ & $(1.38)$ & $(0.65)$ & $(2.04)$ & $(3.11)$ & $(1.95)$ \\
\hline Ineligible for incentive & $1724.8^{* * *}$ & & & $3914.5^{* * *}$ & $2189.6^{* * *}$ \\
\hline$(0 / 1,<60 \%$ reference output $)$ & $(359.38)$ & & & (769.11) & $(449.11)$ \\
\hline \multirow[t]{2}{*}{ Area $\left(\mathrm{km}^{2}\right)$} & $2.432^{* * *}$ & $0.689^{* * *}$ & $2.960 * * *$ & $2.837^{* * *}$ & $3.091^{* * *}$ \\
\hline & $(0.29)$ & $(0.13)$ & $(0.43)$ & $(0.42)$ & $(0.38)$ \\
\hline \multirow[t]{2}{*}{ Grid density $\left(\mathrm{km} / \mathrm{km}^{2}\right)$} & 1.336 & $1.589^{*}$ & -5.235 & 0.822 & -0.809 \\
\hline & $(1.62)$ & $(0.68)$ & $(5.83)$ & $(3.02)$ & $(3.30)$ \\
\hline \multirow[t]{2}{*}{ GDP (billion $€$ ) } & $89.78^{* *}$ & $85.86^{* * *}$ & $153.5^{* * * *}$ & $80.70^{*}$ & $98.95^{* *}$ \\
\hline & $(27.62)$ & (14.35) & $(44.87)$ & $(37.27)$ & $(36.51)$ \\
\hline \multirow[t]{2}{*}{ Population per $\mathrm{km}^{2}$} & $-1.443^{* * *}$ & $-0.715^{* *}$ & $-2.047 * *$ & -0.975 & $-1.652^{* *}$ \\
\hline & $(0.43)$ & $(0.23)$ & $(0.69)$ & $(0.64)$ & $(0.58)$ \\
\hline \multirow[t]{2}{*}{ Land value $\left(€ / \mathrm{m}^{2}\right)$} & $-8.057 * * *$ & $-5.856^{* * *}$ & $-18.43^{* * *}$ & $-8.741^{*}$ & $-10.44^{* * *}$ \\
\hline & $(2.25)$ & $(1.49)$ & $(4.24)$ & $(3.74)$ & $(3.11)$ \\
\hline \multirow[t]{2}{*}{ Green Party votes $(\%$, state $)$} & $-103.1^{*}$ & $131.2^{* *}$ & 212.8 & $-243.7^{* *}$ & -96.32 \\
\hline & $(45.97)$ & $(47.73)$ & (123.99) & (81.14) & $(67.51)$ \\
\hline \multirow[t]{2}{*}{ Green Party votes ( $\%$, federal) } & 99.12 & $-325.5^{* * *}$ & -194.5 & 168.4 & 82.51 \\
\hline & $(63.58)$ & (81.98) & $(140.61)$ & (108.89) & (87.49) \\
\hline \multirow[t]{2}{*}{ Time index } & $2016.1^{* * *}$ & 546.8 & 24081.2 & $39886.7^{*}$ & $4582.4^{* *}$ \\
\hline & $(274.46)$ & (3028.33) & (16528.31) & (19905.18) & $(1524.01)$ \\
\hline \multirow[t]{2}{*}{ Time index squared } & $-188.0 * * *$ & -212.7 & -2485.1 & $-2925.0^{*}$ & $-440.3^{* *}$ \\
\hline & $(32.99)$ & $(907.27)$ & $(2102.36)$ & (1483.43) & (145.55) \\
\hline \multirow[t]{2}{*}{ Time index cubed } & $4.899^{* * * *}$ & 32.84 & 79.50 & 69.96 & $12.52^{* *}$ \\
\hline & (1.19) & (86.02) & (87.73) & (36.53) & $(4.43)$ \\
\hline Counties & 402 & 402 & 402 & 402 & 402 \\
\hline Uncensored observations & 2,173 & 501 & 884 & 788 & 1,672 \\
\hline Observations & 6,030 & 1,608 & 2,010 & 2,412 & 4,422 \\
\hline
\end{tabular}

$* \mathrm{p}<0.10, * * \mathrm{p}<0.05, * * * \mathrm{p}<0.01$, standard errors in parentheses 